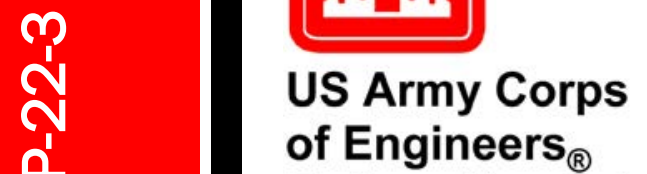

of Engineers ${ }_{\circledast}$

Engineer Research and

Development Center

\title{
Dynamics Modeling and Robotic-Assist, Leader-Follower Control of Tractor Convoys
}

Joshua T. Cook, Laura E. Ray, and James H. Lever

February 2022 
The U.S. Army Engineer Research and Development Center (ERDC) solves the nation's toughest engineering and environmental challenges. ERDC develops innovative solutions in civil and military engineering, geospatial sciences, water resources, and environmental sciences for the Army, the Department of Defense, civilian agencies, and our nation's public good. Find out more at www.erdc.usace.army.mil.

To search for other technical reports published by ERDC, visit the ERDC online library at https://erdclibrary.on.worldcat.org/discovery. 


\title{
Dynamics Modeling and Robotic-Assist, Leader- Follower Control of Tractor Convoys
}

\author{
Joshua T. Cook and Laura E. Ray \\ Thayer School of Engineering \\ Dartmouth College \\ 14 Engineering Drive \\ Hanover, NH 03775 \\ James H. Lever \\ Cold Regions Research and Engineering Laboratory \\ U.S. Army Engineer Research and Development Center \\ 72 Lyme Road \\ Hanover, NH 03775
}

Final report

Approved for public release; distribution is unlimited.

\footnotetext{
Prepared for National Aeronautics and Space Administration Washington, DC 20546

Under NASA grant NNX-10AL97H
} 


\section{Preface}

This study was conducted for the National Aeronautics and Space Administration (NASA) under NASA grant NNX-10AL97H.

The work was performed by the U.S. Army Engineer Research and Development Center, Cold Regions Research Engineering Laboratory (ERDCCRREL) and Dartmouth College. At the time of publication of this paper, the deputy director for ERDC-CRREL was Mr. Bryan E. Baker and the director was Dr. Joseph Corriveau.

This article was originally published online in the Journal of Terramechanics on 27 June 2017.

COL Teresa A. Schlosser was the ERDC commander, and the director was Dr. David W. Pittman.

DISCLAIMER: The contents of this report are not to be used for advertising, publication, or promotional purposes. Citation of trade names does not constitute an official endorsement or approval of the use of such commercial products. All product names and trademarks cited are the property of their respective owners. The findings of this report are not to be construed as an official Department of the Army position unless so designated by other authorized documents. 


\title{
Dynamics modeling and robotic-assist, leader-follower control of tractor convoys
}

\begin{abstract}
This paper proposes a generalized dynamics model and a leader-follower control architecture for skid-steered tracked vehicles towing polar sleds. The model couples existing formulations in the literature for the powertrain components with the vehicle-terrain interaction to capture the salient features of terrain trafficability and predict the vehicles response. This coupling is essential for making realistic predictions of the vehicles traversing capabilities due to the power-load relationship at the engine output. The objective of the model is to capture adequate fidelity of the powertrain and off-road vehicle dynamics while minimizing the computational cost for model based design of leader-follower control algorithms. The leader-follower control architecture presented proposes maintaining a flexible formation by using a look-ahead technique along with a way point following strategy. Results simulate one leader-follower tractor pair where the leader is forced to take an abrupt turn and experiences large oscillations of its drawbar arm indicating potential payload instability. However, the follower tractor maintains the flexible formation but keeps its payload stable. This highlights the robustness of the proposed approach where the follower vehicle can reject errors in human leader driving.
\end{abstract}

(C) 2017 ISTVS. Published by Elsevier Ltd. All rights reserved.

\section{Introduction}

Tracked vehicles have superior mobility in soft terrain when compared with other types of locomotion. This is because the vehicle's weight is distributed over a large area which reduces sinkage and increases traction. The demand for autonomous vehicle systems in soft terrain environments is growing in agriculture, mining, construction and logistics operations. In all of these domains, a heavy duty vehicle is required to operate on a variety of terrains and is pulling or pushing a large payload. Under these circumstances, autonomous systems must account for powertrain dynamics and the terrain-track interaction. These factors have a significant effect on the vehicle dynamics and payload stability due to terrain shearing failure. Most of the literature for autonomous tracked vehicles addresses unloaded vehicles where powertrain capabilities and limitations are discounted. Kitano and Murakami conducted modeling studies on unloaded tracked vehicles to evaluate tracked vehicle dynamics and turning stability using track speeds as model inputs discounting all powertrain effects (Kitano and Jyozaki, 1976; Kitano and Kuma, 1977; Eiyo and Kitano, 1984; Murakami et al., 1992). Le et al. makes the same modeling assumptions (Le et al., 1997). Ferretti modeled an agricultural tracked vehicle using driver torques as model inputs but no powertrain model is discussed (Ferretti and Girelli, 1999). Rubinstein developed a vehicle model including powertrain components, but the 


\section{Nomenclature}

\begin{tabular}{|c|c|}
\hline$A$ & nominal ground contact area $\left(2.97 \mathrm{~m}^{2}\right)$ \\
\hline $\mathbf{B}$ & force vector \\
\hline$b$ & lateral center to center track distance $(2.98 \mathrm{~m})$ \\
\hline$c$ & terrain cohesion $(\mathrm{kPa})$ \\
\hline$D_{L A}$ & look-ahead distance $(\mathrm{m})$ \\
\hline$D_{M}$ & $\begin{array}{l}\text { Hydraulic } \quad \text { Motor } \\
\left(105 \times 10^{-6} \mathrm{~m}^{3} / \text { radian }\right)\end{array}$ \\
\hline$D_{P}$ & Hydraulic Pump Displacement $\left(\mathrm{m}^{3} /\right.$ radian $)$ \\
\hline$D_{P, \operatorname{Max}}$ & $\begin{array}{l}\text { Maximum Hydraulic Pump Displacement } \\
\left(120 \times 10^{-6} \mathrm{~m}^{3} / \text { radian }\right)\end{array}$ \\
\hline$F$ & track traction force $(\mathrm{N})$ \\
\hline$F_{L}$ & left track traction force $(\mathrm{N})$ \\
\hline$F_{R}$ & right track traction force $(\mathrm{N})$ \\
\hline$g_{F D}$ & final drive gear ratio \\
\hline
\end{tabular}

$g_{G R} \quad$ transmission gear ratio

$g_{P} \quad$ hydraulic steering pump gear ratio

$g_{S T} \quad$ hydraulic steering motor gear ratio

$\mathbf{H}_{\mathbf{G}}$ angular momentum about body C.G. $\left(\mathrm{kg} \cdot \mathrm{m}^{2} / \mathrm{s}\right)$

$\mathbf{H}_{\mathrm{L}} \quad$ left driver angular momentum $\left(\mathrm{kg} \cdot \mathrm{m}^{2} / \mathrm{s}\right)$

$\mathbf{H}_{\mathbf{R}}$ right driver angular momentum $\left(\mathrm{kg} \cdot \mathrm{m}^{2} / \mathrm{s}\right)$

$\mathbf{H}_{\mathbf{T}}$ tractor angular momentum $\left(\mathrm{kg} \cdot \mathrm{m}^{2} / \mathrm{s}\right)$

$\mathbf{H}_{\text {SD }}$ sled angular momentum $\left(\mathrm{kg} \cdot \mathrm{m}^{2} / \mathrm{s}\right)$

H angular momentum $\left(\mathrm{kg} \cdot \mathrm{m}^{2} / \mathrm{s}\right)$

$h_{\rho} \quad$ coefficient of lateral resistance offset 0.3004

$i \quad$ track slip ratio $(\%)$

$i_{L} \quad$ left track slip ratio $(\%)$

$i_{R} \quad$ right track slip ratio (\%)

$J_{S} \quad$ driver and track moment of inertia about the $\mathbf{j}_{1}$ axis $\left(300 \mathrm{~kg} \cdot \mathrm{m}^{2}\right)$

$J_{T} \quad$ tractor moment of inertia about the $\mathbf{k}_{1}$ axis $\left(1.5 \times 10^{5} \mathrm{~kg} \cdot \mathrm{m}^{2}\right)$

$J_{S D} \quad$ sled moment of inertia about the $\mathbf{k}_{3}$ axis $\left(3.98 \times 10^{6} \mathrm{~kg} \cdot \mathrm{m}^{2}\right)$

$J_{e} \quad$ engine moment of inertia $\left(15 \mathrm{~kg} \cdot \mathrm{m}^{2}\right)$

$J_{t} \quad$ transmission moment of inertia $\left(150 \mathrm{~kg} \cdot \mathrm{m}^{2}\right)$

$K_{d c} \quad$ transfer function dc gain $\left((\mathrm{m} / \mathrm{s})^{-1}\right)$

$K_{i, v} \quad$ integral heading controller gain (deg/deg)

$K_{i, v} \quad$ integral speed controller gain $\left((\mathrm{m} / \mathrm{s})^{-1}\right)$

$K_{p, \theta} \quad$ proportional heading controller gain (deg/deg)

$K_{p, v} \quad$ proportional speed controller gain $\left((\mathrm{m} / \mathrm{s})^{-1}\right)$

$k \quad$ speed reference gain $(\mathrm{m} / \mathrm{s})$

$K$ terrain shear deformation modulus $(\mathrm{cm})$

$k_{c} \quad$ modulus of terrain cohesion $(\mathrm{kPa})$

$k_{\Phi} \quad$ modulus of terrain friction angle (deg)

$L_{A} \quad$ drawbar length $(1 \mathrm{~m})$

$L_{S D} \quad$ sled length $(21 \mathrm{~m})$

$L_{T A} \quad$ tractor CG to drawbar distance $(0.82 \mathrm{~m})$

$L_{T A} \quad$ tractor CG to drawbar distance $(1 \mathrm{~m})$

$l \quad$ nominal track ground contact length $(3.25 \mathrm{~m})$

$L_{T S} \quad$ rigid truss length $(6 \mathrm{~m})$

M mass matrix

$m_{B} \quad$ bladder mass $(10,000 \mathrm{~kg})$
$m_{T} \quad$ tractor mass $(25,000 \mathrm{~kg})$

$m_{S D} \quad$ sled mass $(80,000 \mathrm{~kg})$

$m_{\rho} \quad$ slope coefficient of lateral resistance $(-0.0433)$

$n$ modulus of terrain exponent

$P_{E} \quad$ engine power $(\mathrm{kW})$

$P_{h} \quad$ pressure in $h$ section of hose $(\mathrm{Pa})$

$Q_{h} \quad$ hydraulic fluid flow in the $h$ section of hose $\left(\mathrm{m}^{3} / \mathrm{s}\right)$

$Q_{j} \quad j$ th generalized force

$q_{j} \quad j$ th generalized coordinate

$R \quad$ track resistance force $(\mathrm{N})$

$R_{L} \quad$ longitudinal left track resistance force $(\mathrm{N})$

$R_{R} \quad$ longitudinal left track resistance force $(\mathrm{N})$

$R_{c} \quad$ terrain compaction resistance $(\mathrm{N})$

$R_{S D, X} \quad$ sled resistance force in $\mathbf{i}_{3}$ direction $(\mathrm{N})$

$R_{S D, Y} \quad$ sled resistance force in $\mathbf{j}_{3}$ direction (N)

$R_{l L F} \quad$ lateral resistance force, left track, front section (N)

$R_{l L R} \quad$ lateral resistance force, left track, rear section (N)

$R_{l R F} \quad$ lateral resistance force, right track, front section (N)

$R_{l R R} \quad$ lateral resistance force, right track, rear section (N)

$\mathbf{R}_{A / B}$ rotation transformation from frame B to A

$s$

$S D$

$T \quad$ kinetic energy (J)

$V_{h} \quad$ volume of $h$ section of hose $6.6 \times 10^{-3} \mathrm{~m}^{3}$

$\mathbf{r}_{P / O} \quad$ position vector from point $\mathrm{O}$ to $\mathrm{P}(\mathrm{m})$

$\mathbf{r}_{S D / T}$ position vector from the tractor C.G. to the sled C.G. (m)

$\mathbf{r}_{T / O} \quad$ position vector from the inertial frame origin to tractor C.G. (m)

velocity $(\mathrm{m} / \mathrm{s})$

v

$\mathbf{v}_{G}$

$\mathbf{v}_{T}$

$\mathbf{v}_{S D}$

$v_{x}$

$v_{y}$

$v_{\text {leader }}$

$v_{\text {ref }}$

$W$

$W P$

X

velocity of body C.G. (m/s)

velocity of tractor $(\mathrm{m} / \mathrm{s})$

velocity of sled $(\mathrm{m} / \mathrm{s})$

tractor $\mathbf{i}_{1}$ velocity $(\mathrm{m} / \mathrm{s})$

tractor $\mathbf{j}_{1}$ velocity $(\mathrm{m} / \mathrm{s})$

leader vehicle velocity $(\mathrm{m} / \mathrm{s})$

controller reference velocity $(\mathrm{m} / \mathrm{s})$

normal load of track segment on terrain $(\mathrm{N})$

x state vector

$x_{e} \quad$ follower longitudinal offset error (m)

$Y \quad \mathbf{J}$ tractor position in inertial frame (m)

$z \quad$ track sinkage $(\mathrm{m})$

$\alpha \quad$ steering angle (deg)

$\beta \quad$ hydraulic fluid bulk modulus $\left(2.79 \times 10^{9} \mathrm{~Pa}\right)$

$\chi \quad$ engine throttle dilation

$\delta \quad$ transfer function time constant (s) 


\begin{tabular}{|c|c|c|c|}
\hline$\delta_{t}$ & gear shift time constant $(0.25 \mathrm{~s})$ & $\rho$ & radius of curvature (rad) \\
\hline$\eta$ & sled resistance coefficient $(0.11)$ & $\tau_{E, \operatorname{Max}}$ & maximum available engine torque at a given en- \\
\hline$\Gamma$ & normalized wet friction clutch command $(\mathrm{N} \cdot \mathrm{m})$ & & gine speed $(\mathrm{N} \cdot \mathrm{m})$ \\
\hline$\lambda$ & wet friction clutch viscous coefficient $\left(1 \mathrm{~s}^{-1}\right)$ & $\tau_{L}$ & left track or drive torque $(\mathrm{N} \cdot \mathrm{m})$ \\
\hline$\mu_{S}$ & $\begin{array}{l}\text { lateral resistance coefficient based on } \mathrm{z} \\
\left(10 \mathrm{~kg} \cdot \mathrm{m}^{2} / \mathrm{s}\right)\end{array}$ & $\begin{array}{l}\tau_{M} \\
\tau_{P}\end{array}$ & $\begin{array}{l}\text { hydraulic motor output torque }(\mathrm{N} \cdot \mathrm{m}) \\
\text { hydraulic pump load torque on engine }(\mathrm{N} \cdot \mathrm{m})\end{array}$ \\
\hline$\Omega$ & engine speed (RPM) & $\tau_{R}$ & right track or drive torque $(\mathrm{N} \cdot \mathrm{m})$ \\
\hline$\omega$ & angular velocity $(\mathrm{rad} / \mathrm{s})$ & $\tau_{f, d}$ & wet friction clutch dynamic torque $(\mathrm{Nm})$ \\
\hline $\begin{array}{l}\omega_{L} \\
\omega_{R}\end{array}$ & $\begin{array}{l}\text { left track or driver angular velocity }(\mathrm{rad} / \mathrm{s}) \\
\text { right track or driver angular velocity }(\mathrm{rad} / \mathrm{s})\end{array}$ & $\tau_{f, \max , d}$ & $\begin{array}{l}\text { wet friction clutch maximum dynamic torque } \\
\text { threshold }(1800 \mathrm{Nm})\end{array}$ \\
\hline$\omega_{E}$ & engine speed $(\mathrm{rad} / \mathrm{s})$ & $\tau_{f, \max , s}$ & wet friction clutch maximum static torque \\
\hline$\omega_{t, \text { out }}$ & $\begin{array}{l}\text { transmission rotational output shaft speed (rad/ } \\
\text { s) }\end{array}$ & $\begin{array}{l}\tau_{f, s} \\
\tau_{t, i n}\end{array}$ & $\begin{array}{l}\text { wet friction clutch static torque }(\mathrm{Nm}) \\
\text { transmission input torque }(\mathrm{N} \cdot \mathrm{m})\end{array}$ \\
\hline$\Phi$ & terrain friction angle (rad) & $\tau_{t, \text { out }}$ & transmission output torque $(\mathrm{N} \cdot \mathrm{m})$ \\
\hline$\Pi$ & normalized engine throttle command & $\theta$ & tractor orientation in the inertial frame (rad) \\
\hline $\begin{array}{l}\phi \\
\psi\end{array}$ & $\begin{array}{l}\text { drawbar orientation relative to frame } 1(\mathrm{rad}) \\
\text { sled orientation relative to frame } 1(\mathrm{rad})\end{array}$ & $\zeta$ & $\begin{array}{l}\text { track or driver damping coefficient } \\
\left(10 \mathrm{~kg} \cdot \mathrm{m}^{2} / \mathrm{s}\right)\end{array}$ \\
\hline$\varphi_{L}$ & left track or driver angular position (rad) & $\zeta_{e}$ & engine damping coefficient $\left(1 \mathrm{~kg} \cdot \mathrm{m}^{2} / \mathrm{s}\right)$ \\
\hline$\varphi_{R}$ & right track or driver angular position (rad) & $\zeta_{t}$ & transmission damping coefficient $\left(10 \mathrm{~kg} \cdot \mathrm{m}^{2} / \mathrm{s}\right)$ \\
\hline
\end{tabular}

terrain-track interaction fidelity is beyond the requirements for control law development, and no payload is present (Rubinstein and Hitron, 2004).

In this paper we have developed a comprehensive tracked vehicle model for numerical experiments with autonomous tractors. The model encompasses all the of the salient features that significantly effect the vehicle's dynamics under load on deformable terrain in a simulation test bed while minimizing the computational cost. These salient features are the driver inputs, the powertrain model, Wong terramechanics theory that adequately captures the terrain-track interaction, the relationship between a given payload and the load it places on the vehicle drawbar, and multi-body dynamics. These features are all coupled together as the powertrain puts limitations on the vehicle's capabilities due to the terrain-vehicle interaction and payload. The model's balance between fidelity and computational cost makes it a powerful tool for iterative model based design for general purpose unmanned tractor systems and their controller designs due to fast simulation times.

The work is motivated by the US Antarctic Program's (USAP) South Pole Traverse (SPT) which resupplies the National Science Foundation's South Pole Research Station from McMurdo Station. Presently, traverse operations use two fleets for two round trips each season where each fleet consists of eight tractors and an eight-person crew. These trips via ground offset the number of LC130 flights required to transport cargo and fuel providing an economic benefit of $\$ 2 \mathrm{M}$ per trip. Each trip currently takes 50 days but if an effective manned leader, autonomous follower robotic assist technology can be deployed, further savings can be unlocked by reducing this round trip time to allow for increased ground transport. The current towing configuration uses polar sleds that are most commonly loaded with fuel bladders (Lever and Weale, 2012). The low resistance forces between the sled and snow allow tractors to pull large payloads $(80,000 \mathrm{~kg})$. However, autonomous tractors equipped with polar sleds raises concerns of payload stability as the payload is free to swing about the drawbar. Furthermore, the Antarctic continent provides a unique challenge for implementation as there are large amounts of spatial and temporal terrain variation due to unpredictable weather and snowfall. The variation in terrain can significantly impact the vehicle dynamics, mobility, and payload stability. The model allows for exhaustive numerical experiments to test controllers and automation strategies across different payloads, the vehicle's bounded state space, and the terrain parameter space.

The manned leader, autonomous follower robotic assist approach proposed in this paper is limited to a single follower although it can readily be applied to multiple followers. Emphasis is placed on maintaining a flexible formation rather than focusing on the follower's convergence to a reference trajectory (Barfoot and Clark, 2004; Low, 2015). This allows the follower to use its leader's trajectory as a guide rather than a strict reference input so that human error in driving is rejected for robust payload stability. This is done using a look-ahead approach with a sequence of way points as a guide that are user defined offsets of the leader's path. It is assumed that communication between vehicles and accurate measurements of vehicle GPS position, speed, and heading update at $10 \mathrm{~Hz}$. These rates are based on autonomous tractor hardware used in Zhang et al. (2009). Simulation results demonstrate the effectiveness of the proposed approach. 
The remainder of the paper is organized as follows: Section 2 goes over the tractor-sled towing configuration as it relates to the assumptions for the Lagrange multi-body dynamics derivation, Bekker-Wong terramechanics, and the powertrain model. Section 3 goes over in detail the proposed leader-follower control strategy. Section 4 shows simulation results and demonstrates the robustness of the proposed control approach.

\section{Dynamics modeling}

\subsection{Tractor-sled configuration}

The multi-body dynamics derivation is based on the current towing configuration used by the South Pole Traverse, which uses Caterpillar and AGCO MT865 tractors (Caterpillar, Inc (Peoria, Ill.) and AGCO Corporation (Duluth, GA.)) and a sled system towing eight fuel bladders. A picture and diagram of the setup are shown in Figs. 1 and 2 respectively. Documentation and data for the tractor and sled configuration can be found in Lever and Weale (2012) and Caterpillar (2002). A free body diagram of the tractor-sled vehicle is illustrated in Fig. 3 labeling all coordinate axes and forces. The four coordinate axes comprise the inertial frame and 3 body fixed frames. The $X, Y$ axis, frame 0 , denotes the inertial frame, the $x_{1}, y_{1}$ axis, frame 1 , is fixed to the C.G. of the tractor, the $x_{2}, y_{2}$ axis, frame 2 , is fixed to the drawbar at the point where it connects to the tractor underneath the vehicle body, and the $x_{3}, y_{3}$ axis, frame 3 , is fixed to the sled at the point where it con- nects to the drawbar. The orientations of frames 2 and 3 are referenced from frame 1 by the angles $\phi$ and $\psi$ respectively. The forces shown in Fig. 3 consist of traction and resistive forces denoted as $F$ and $R . F_{R}, F_{L}, R_{R}$, and $R_{L}$ refer to longitudinal traction and resistive forces of the right and left tracks where the right and left track are specified in the subscripts $R$ and $L . R_{l x x}$ denotes a lateral resistance force on the track denoted with the first subscript $l$. Subsequent subscripts specify the right or left track as $R$ or $L$ and the front or rear of that track as $F$ or $R$. As an example, $R_{l R F}$ refers to the lateral resistance force on the right track at the front. Modeling methods for these forces are covered in the terramechanics section.

\subsection{Rigid body dynamics Lagrange derivation}

The multi-body dynamics model of the tractor-sled system presented is derived using Lagranges equation

$\frac{d}{d t} \frac{\partial T}{\partial \dot{q}_{j}}-\frac{\partial T}{\partial \dot{q}}=Q_{j} \quad \forall j$

where $T$ is the total kinetic energy, $q_{j}$ is the $j$ th generalized coordinate, and $Q_{j}$ are the generalized forces for the $j$ th generalized coordinate. The generalized coordinates for the system are chosen as the tractor $X, Y$ position in the inertial frame, the tractor heading angle $\theta$, the drawbar orientation relative to the tractor $\phi$, the sled orientation relative to the tractor $\psi$, and the left and right driver angular positions $\varphi_{L}$ and $\varphi_{R}$. The kinetic energy for any rigid body can be written as

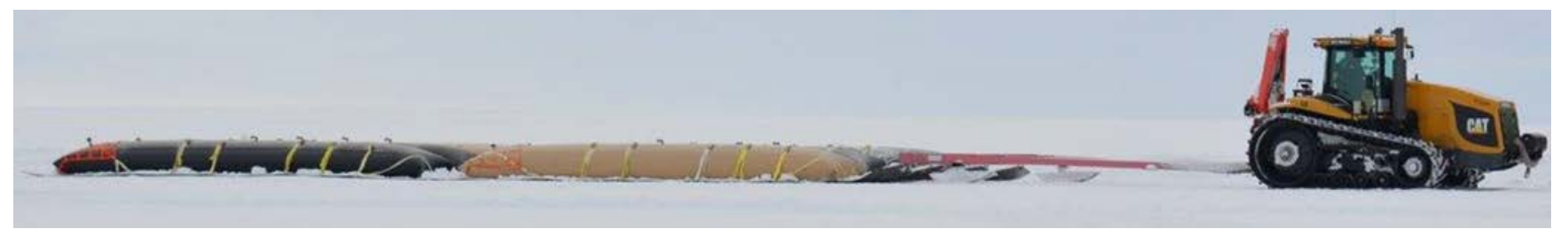

Fig. 1. South Pole Traverse tractor and sled configuration.

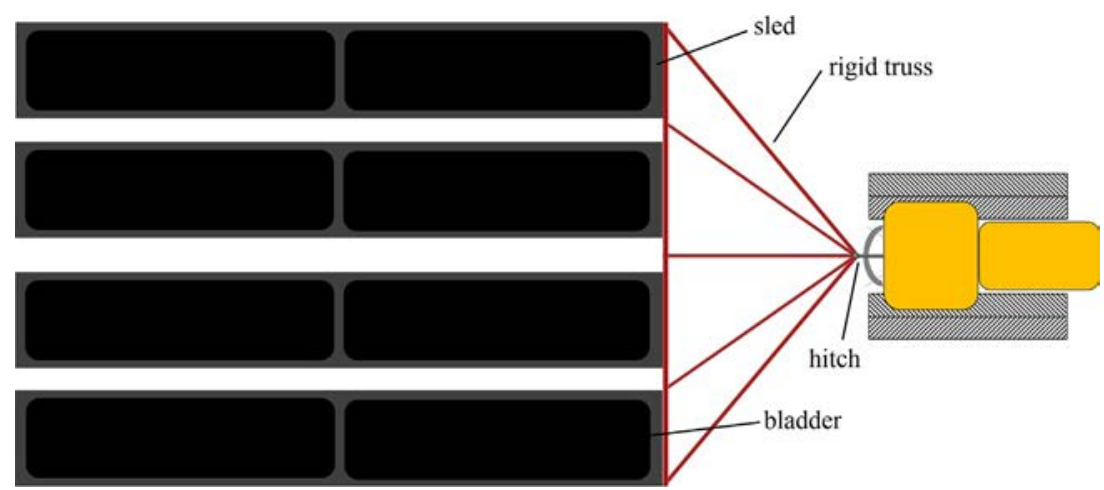

Fig. 2. Diagram of the South Pole Traverse tractor-sled towing configuration. Sleds are attached to the rigid, red truss where fuel bladders rest on top. The red truss inserts at the drawbar hitch of the tractor. (For interpretation of the references to color in this figure legend, the reader is referred to the web version of this article.) 


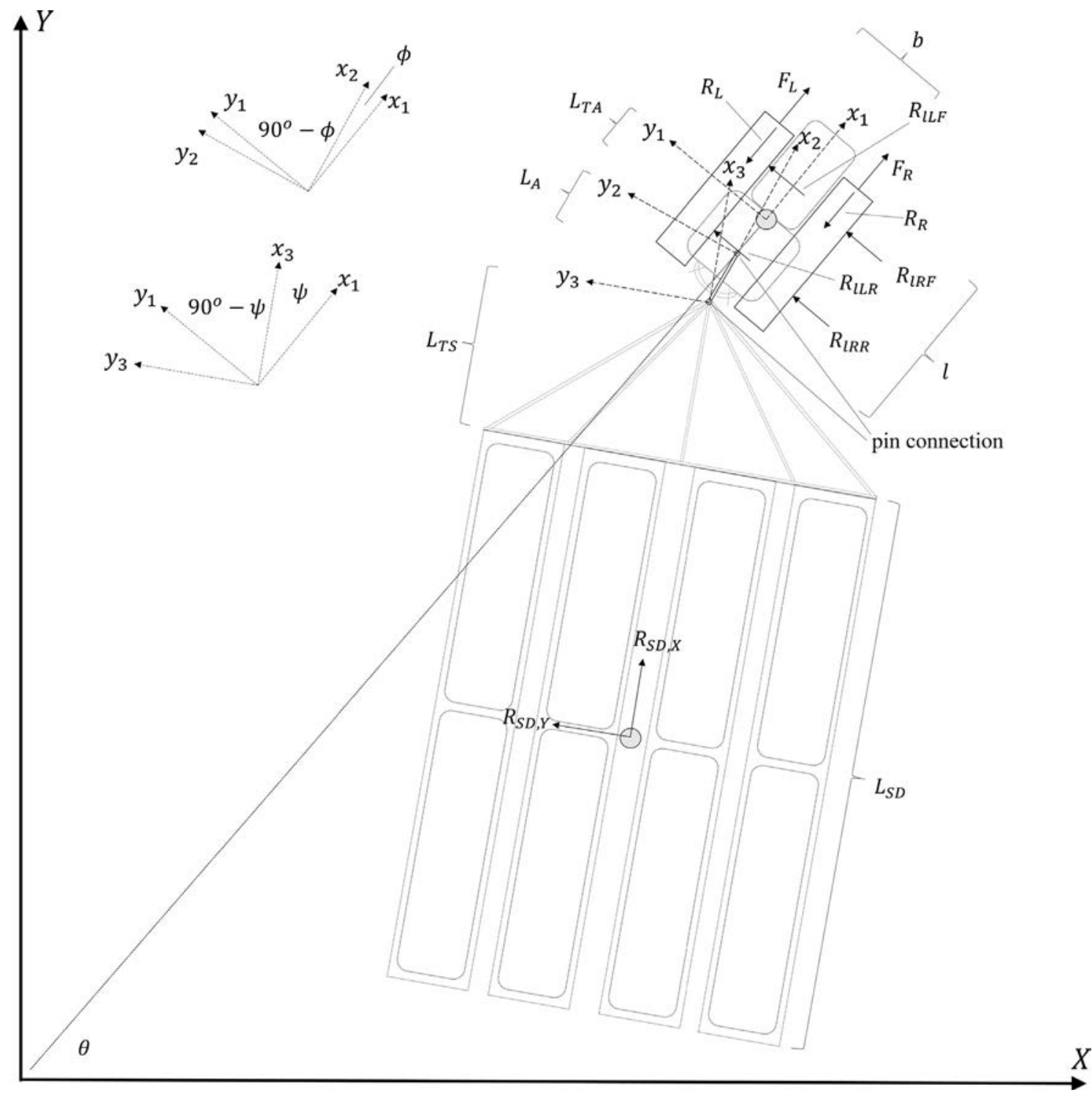

Fig. 3. Free body diagram of the tractor-sled vehicle. Constraint forces between rigid bodies are omitted as they are not required for the Lagrangian derivation.

$T=\frac{1}{2} m \mathbf{v}_{G} \cdot \mathbf{v}_{G}+\frac{1}{2} \omega_{G} \cdot \mathbf{H}_{G}$

where $\mathbf{v}$ is the velocity, $\boldsymbol{\omega}$ is the angular velocity, $\mathbf{H}$ is angular momentum, and the subscript $G$ denotes the center of mass of the body. In this derivation, the red truss on the sled and the drawbar in gray attached to the tractor shown in Figs. 1-3 are assumed to have negligible mass relative to the tractor $(25,000 \mathrm{~kg})$ and sled load $(80,000 \mathrm{~kg})$. In addition, the translational kinetic energy in the $X-Y$ plane and rotational kinetic energy about the $Z$ axis of the two tracks are combined with the rest of the tractor. Therefore, the kinetic energy of the system is defined as

$$
\begin{aligned}
T= & \frac{1}{2} m_{T} \mathbf{v}_{T} \cdot \mathbf{v}_{T}+\frac{1}{2} \omega_{T} \cdot \mathbf{H}_{T}+\frac{1}{2} m_{S D} \mathbf{v}_{S D} \cdot \mathbf{v}_{S D} \\
& +\frac{1}{2} \omega_{S D} \cdot \mathbf{H}_{S D}+\frac{1}{2} \omega_{L} \cdot \mathbf{H}_{L}+\frac{1}{2} \omega_{R} \cdot \mathbf{H}_{R}
\end{aligned}
$$

where the subscripts $T, S D, L$, and $R$ refer to the tractor, sled, and left and rights tracks. The model being derived is planar, so the velocities of the rigid bodies and rotational energy terms are defined as

$$
\begin{aligned}
\mathbf{v}_{T}= & \frac{d}{d t} \mathbf{r}_{T / O}=\frac{d}{d t}(X \mathbf{I}+Y \mathbf{J}) \\
\mathbf{v}_{S D} & =\frac{d}{d t}\left(\mathbf{r}_{S D / T}+\mathbf{r}_{T / O}\right) \\
& =\frac{d}{d t}\left(X \mathbf{I}+Y \mathbf{J}-\mathbf{R}_{1 / 0}^{T} L_{T A} \mathbf{i}_{1}-\mathbf{R}_{2 / 0}^{T} L_{A} \mathbf{i}_{2}\right) \\
& -\mathbf{R}_{3 / 0}^{T}\left(\frac{1}{2} L_{S D}+L_{T S}\right) \mathbf{i}_{3} \\
\mathbf{R}_{1 / 0} & =\left[\begin{array}{ccc}
\cos \theta & \sin \theta & 0 \\
-\sin \theta & \cos \theta & 0 \\
0 & 0 & 1
\end{array}\right]
\end{aligned}
$$




$$
\begin{aligned}
& \mathbf{R}_{2 / 0}=\left[\begin{array}{ccc}
\cos \phi & \sin \phi & 0 \\
-\sin \phi & \cos \phi & 0 \\
0 & 0 & 1
\end{array}\right] \mathbf{R}_{1 / 0} \\
& \mathbf{R}_{3 / 0}=\left[\begin{array}{ccc}
\cos \psi & \sin \psi & 0 \\
-\sin \psi & \cos \psi & 0 \\
0 & 0 & 1
\end{array}\right] \mathbf{R}_{1 / 0} \\
& \frac{1}{2} \omega_{G} \cdot \mathbf{H}_{G}=\frac{1}{2} J_{T} \dot{\theta}^{2} \\
& \frac{1}{2} \omega_{S D} \cdot \mathbf{H}_{S D}=\frac{1}{2} J_{S D}(\dot{\theta}+\dot{\psi})^{2} \\
& \frac{1}{2} \omega_{L} \cdot \mathbf{H}_{L}=\frac{1}{2} J_{S} \dot{\varphi}_{L}^{2} \\
& \frac{1}{2} \omega_{R} \cdot \mathbf{H}_{R}=\frac{1}{2} J_{S} \dot{\varphi}_{R}^{2}
\end{aligned}
$$

where $L_{T A}$ is the distance from the tractor CG to the drawbar, $L_{A}$ is the drawbar length, $L_{T S}$ is the truss length, and $L_{S D}$ is the sled length. Rotational transformation matrices are generally defined as $\mathbf{R}_{A / B}$, where the rotation is from frame $B$ to frame $A$. From the definition of the kinetic energy, the full and partial derivatives can be taken on the left side of Eq. (1) for all the generalized coordinates. The next step is to define the generalized forces, which do virtual work through virtual displacements of the generalized coordinates and are given by

$Q_{j}=\sum_{P} \mathbf{F}_{P} \cdot \frac{\partial}{\partial q_{j}} \mathbf{r}_{P / O}+\sum_{K} \boldsymbol{\Gamma}_{K} \cdot \frac{\partial}{\partial q_{j}} \boldsymbol{\theta}_{K} \quad \forall j$

where $\mathbf{F}_{P}$ is an arbitrary force vector that acts at $\mathbf{r}_{P / O}$ and $\boldsymbol{\Gamma}_{K}$ is an arbitrary torque vector acting on body $K$ with an angular position $\boldsymbol{\theta}_{K}$. For the derivation of the tractorsled system, the terms in Eq. (13) are evaluated as

$$
\begin{aligned}
\sum_{P} \mathbf{F}_{P} \cdot \frac{\partial}{\partial q_{j}} \mathbf{r}_{P / O}= & \mathbf{R}_{1 / 0}^{T} F_{L} \mathbf{i}_{1} \cdot \frac{\partial}{\partial q_{j}}\left(\mathbf{r}_{T / O}+\mathbf{R}_{1 / 0}^{T} \frac{b}{2} \mathbf{j}_{1}\right) \\
& +\mathbf{R}_{1 / 0}^{T} F_{R} \mathbf{i}_{1} \cdot \frac{\partial}{\partial q_{j}}\left(\mathbf{r}_{T / O}-\mathbf{R}_{1 / 0}^{T} \frac{b}{2} \mathbf{j}_{1}\right) \\
& -\mathbf{R}_{1 / 0}^{T} R_{L} \mathbf{i}_{1} \cdot \frac{\partial}{\partial q_{j}}\left(\mathbf{r}_{T / O}+\mathbf{R}_{1 / 0}^{T}\left(\frac{l}{2} \mathbf{i}_{1}+\frac{b}{2} \mathbf{j}_{1}\right)\right) \\
& -\mathbf{R}_{1 / 0}^{T} R_{R} \mathbf{i}_{1} \cdot \frac{\partial}{\partial q_{j}}\left(\mathbf{r}_{T / O}+\mathbf{R}_{1 / 0}^{T}\left(\frac{l}{2} \mathbf{i}_{1}-\frac{b}{2} \mathbf{j}_{1}\right)\right) \\
& +\mathbf{R}_{1 / 0}^{T} R_{L L F} \mathbf{j}_{1} \cdot \frac{\partial}{\partial q_{j}}\left(\mathbf{r}_{T / O}+\mathbf{R}_{1 / 0}^{T}\left(\frac{l}{2} \mathbf{i}_{1}+\frac{b}{2} \mathbf{j}_{1}\right)\right) \\
& +\mathbf{R}_{1 / 0}^{T} R_{l R F} \mathbf{j}_{1} \cdot \frac{\partial}{\partial q_{j}}\left(\mathbf{r}_{T / O}+\mathbf{R}_{1 / 0}^{T}\left(\frac{l}{2} \mathbf{i}_{1}-\frac{b}{2} \mathbf{j}_{1}\right)\right) \\
& +\mathbf{R}_{1 / 0}^{T} R_{l L R} \mathbf{j}_{1} \cdot \frac{\partial}{\partial q_{j}}\left(\mathbf{r}_{T / O}+\mathbf{R}_{1 / 0}^{T}\left(-\frac{l}{2} \mathbf{i}_{1}+\frac{b}{2} \mathbf{j}_{1}\right)\right) \\
& +\mathbf{R}_{1 / 0}^{T} R_{l R R} \mathbf{j}_{1} \cdot \frac{\partial}{\partial q_{j}}\left(\mathbf{r}_{T / O}+\mathbf{R}_{1 / 0}^{T}\left(-\frac{l}{2} \mathbf{i}_{1}-\frac{b}{2} \mathbf{j}_{1}\right)\right) \\
& +\mathbf{R}_{3 / 0}^{T}\left(R_{S D, X} \mathbf{i}_{3}+R_{S D, Y} \mathbf{j}_{3}\right) \cdot \frac{\partial}{\partial q_{j}}\left(\mathbf{r}_{S D / T}+\mathbf{r}_{T / O}\right)
\end{aligned}
$$

$$
\begin{aligned}
\sum_{K} \boldsymbol{\Gamma}_{K} \cdot \frac{\partial}{\partial q_{j}} \boldsymbol{\theta}_{K}= & \left(\tau_{L}-F_{L} r-\zeta \dot{\varphi}_{L}\right) \mathbf{j}_{1} \cdot \frac{\partial}{\partial q_{j}}\left(\varphi_{L} \dot{\mathbf{j}}_{1}+\theta \mathbf{k}_{1}\right) \\
& +\left(\tau_{R}-F_{R} r-\zeta \dot{\varphi}_{R}\right) \mathbf{j}_{1} \cdot \frac{\partial}{\partial q_{j}}\left(\varphi_{R} \mathbf{j}_{1}+\theta \mathbf{k}_{1}\right)
\end{aligned}
$$

This derivation gives the differential equations for the rigid body dynamics of the tractor sled system in terms of $\ddot{X}$ and $\ddot{Y}$. However, the motivation for the model is autonomous vehicle control, so we make substitutions to rewrite the equations in terms of $\dot{v}_{x}$ and $\dot{v}_{y}$ corresponding to the longitudinal and lateral velocity of the tractor in frame 1 . The velocity of the tractor can be written as

$\dot{X}=v_{x} \cos \theta-v_{y} \sin \theta$

$\dot{Y}=v_{y} \cos \theta+v_{x} \sin \theta$

and then differentiated

$\ddot{X}=\dot{v}_{x} \cos \theta-\dot{v}_{y} \sin \theta-\dot{\theta}\left(v_{y} \cos \theta+v_{x} \sin \theta\right)$

$\ddot{Y}=\dot{v}_{y} \cos \theta+\dot{v}_{x} \sin \theta+\dot{\theta}\left(v_{x} \cos \theta-v_{y} \sin \theta\right)$

Using Eqs. (18) and (19) for substitution, the equations of motion can be written in terms of the body fixed tractor velocities as $\dot{\mathbf{x}}=f(\mathbf{x})$, where the state vector is defined in Eq. (20).

$$
\mathbf{x} \equiv\left[\begin{array}{llllllllllll}
X & Y & \theta & \phi & \psi & v_{x} & v_{y} & \dot{\theta} & \dot{\phi} & \dot{\psi} & \dot{\varphi}_{L} & \dot{\varphi}_{R}
\end{array}\right]^{T}
$$

$\dot{\mathbf{x}}=\mathbf{M}^{-1} \mathbf{B}(\mathbf{x})$

Definitions for the mass matrix $\mathbf{M}_{7 x 7}$ and the force vector $\mathbf{B}_{7 x 1}$ are given in Appendix A.

\subsection{Terramechanics}

The tractor-sled vehicle interacts with the terrain at its tracks and at the sled. This section covers the models used for both of these interactions in this order. The modeling techniques for the track forces are from Wong (2008). Different approaches for modeling the terrain-track interaction exist with varying orders of complexity from empirical, semi-empirical, to complex finite element modeling. In this work, we use semi-empirical BekkerWong theory and assume a uniform pressure distribution along the contact length of the track. This theory is well established and provides reasonably accurate predictions for heavy duty tracked vehicles. An additive benefit of this approach is that no numerical integration is required as all expressions are in closed form. This alleviates unnecessary computational load and allows for faster iteration in controller tuning. A free body diagram of all the track forces is shown in Fig. 4. The driver torque from the output of the powertrain $\tau$, the traction force, $F$, and compaction resistance, $R_{c}$, are denoted as blue arrows. The lateral resistance forces, $R_{l}$, are shown as green arrows. All of these forces are functions of slip, vehicle parameters, and terrain parameters. The traction, compaction resistance and sinkage for a single track are given by 


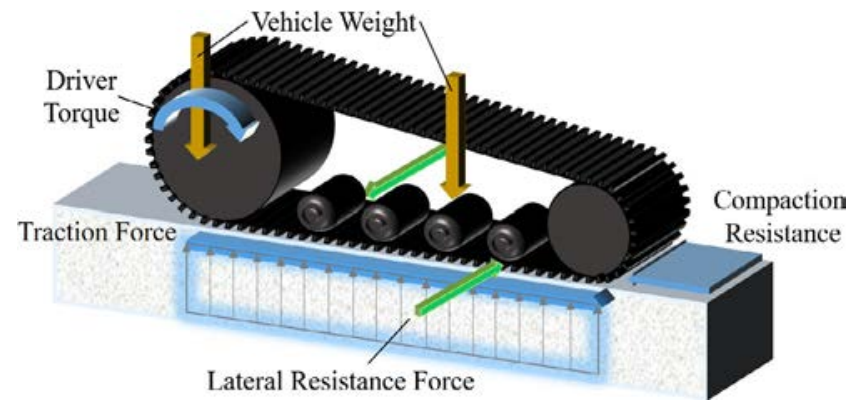

Fig. 4. Track free body diagram.

$F=(A c+W \tan \Phi)\left(1-\frac{K}{i l}\left(1-e^{\frac{i l}{K}}\right)\right)$

$R_{c}=b\left(\frac{k_{c}}{b}+k_{\Phi}\right) \frac{z^{n+1}}{n+1}$

$z=\left(\frac{W / A}{\left(k_{c} / b\right)+k_{\Phi}}\right)^{1 / n}$

where $A$ is the nominal ground contact area of one track, $c$ is the terrain cohesion, $W$ is the normal load for one track on the terrain, $\Phi$ is the terrain friction angle, $K$ is the terrain shear deformation modulus, $i$ is the slip ratio, $k_{c}$ is the cohesive modulus of terrain deformation, $k_{\Phi}$ is the friction modulus of terrain deformation, $n$ is the exponent of terrain deformation, and $z$ is the sinkage. Eqs. (22)-(24) summarize Bekker-Wong terramechanics theory and dictate the longitudinal motion of the vehicle (Wong, 2008).

As a vehicle attempts to turn however, additional lateral resistive forces act on the vehicle tracks. There is no well established method for determining these forces based on Bekker-Wong terrain parameters. However, experimental data shows that these forces depend on the normal load on the terrain, the vehicle turning radius, and vehicle speed (Wong, 2008). Since SPT uses agricultural tractors, we omit any dependence on speed since there is a limited operating range approximately between $[0,4] \mathrm{m} / \mathrm{s}$. The equation for the lateral resistance force is given by

$R_{l}=-\operatorname{sign}\left(v_{y, \text { track }}\right)\left(\mu_{r}(\rho)+\mu_{z}(z)\right) W$

where $v_{y, \text { track }}$ is the velocity of the track segment in the $\mathbf{j}_{1}$ direction, $\mu_{r}$ is the lateral resistance coefficient based on the turning radius, $\rho$, and $\mu_{z}$ is the coefficient of lateral turning resistance based on the sinkage at the given track segment. To calculate $\mu_{r}$, a log linear approximation is made based on data trends provided in Wong (2008) and is given by

$\mu_{r}=-m_{\rho} \log (\rho)+h_{\rho}$

where $m_{\rho}$ and $h_{\rho}$ are the coefficients for the slope and offset. There is not an established method for calculating the lateral resistance coefficient due to sinkage $\mu_{z}$ but it is postulated that it does have a notable impact on the vehicle's trajectory and is a function of existing terrain parameters. Therefore, this is left as an input to the model.
The model for the sled friction forces is derived from data and methods in Lever and Weale (2012). The data provided measures the drawbar pull directly at the tractor hitch. Here we use this data to empirically model the frictional force at the sled snow interface using a resistance coefficient $\eta$ and bound it between 0.03 and 0.13 :

$R_{S D}=\eta m_{B} g N$

$R_{S D}=\sqrt{R_{S D, X}^{2}+R_{S D, Y}^{2}}$

$m_{B} g$ is the weight of one bladder, and $N$ is the number of bladders. It is assumed that the resistance force acts in the opposite direction of the sled's velocity. Since $R_{S D, X}$ and $R_{S D, Y}$ are defined as body fixed in the Lagrange derivation, the velocity of the sled as defined in frame 3 must be computed. The sled velocity and resistance forces are given by

$$
\begin{aligned}
\mathbf{v}_{S D}= & v_{x} \mathbf{i}_{1}+v_{y} \mathbf{j}_{1}+\mathbf{R}_{3 / 1}\left(\dot{\theta} \mathbf{k}_{1} \times-L_{T A} \mathbf{i}_{1}\right)+\mathbf{R}_{3 / 2}\left(\dot{\phi} \mathbf{k}_{2} \times-L_{A} \mathbf{i}_{2}\right) \\
+ & \left(\dot{\psi} \mathbf{k}_{3} \times-\left(\frac{1}{2} L_{S D}+L_{T S}\right) \mathbf{i}_{3}\right) \\
\mathbf{R}_{3 / 1}= & {\left[\begin{array}{ccc}
\cos \psi & \sin \psi & 0 \\
-\sin \psi & \cos \psi & 0 \\
0 & 0 & 1
\end{array}\right] } \\
\mathbf{R}_{3 / 2}= & {\left[\begin{array}{ccc}
\cos (\psi-\phi) & \sin (\psi-\phi) & 0 \\
-\sin (\psi-\phi) & \cos (\psi-\phi) & 0 \\
0 & 0 & 1
\end{array}\right] } \\
R_{S D, X}= & R_{S D}\left(\frac{-\mathbf{v}_{S D} \cdot \mathbf{i}_{3}}{\left\|\mathbf{v}_{S D}\right\|}\right) \\
R_{S D, Y}= & R_{S D}\left(\frac{-\mathbf{v}_{S D} \cdot \mathbf{j}_{3}}{\left\|\mathbf{v}_{S D}\right\|}\right)
\end{aligned}
$$

\subsection{Power-train modeling}

This section covers the specific modeling approaches used for each powertrain component. Fig. 5 shows an overview of the major powertrain components.

\subsubsection{Engine model}

The engine model is created by fitting a 3rd order polynomial to torque-speed engine data, which is provided in Caterpillar (2002). Fig. 6 shows the resulting model for an MT865 Challenger Model Tractor. The engine model is valid for the allowable operating engine speed range, i.e., engine speed $\Omega \in[1300,2300]$ RPM. The polynomial curve fit is referred to as an engine torque or engine power demand function $g(\Omega)$ and provides the maximum amount of power available at a given engine speed whose form is given by

$$
\begin{aligned}
& g(\Omega)=P_{\max }\left(a n+b n^{2}-c n^{3}\right) \\
& n \equiv \frac{\Omega}{\Omega_{0}}
\end{aligned}
$$




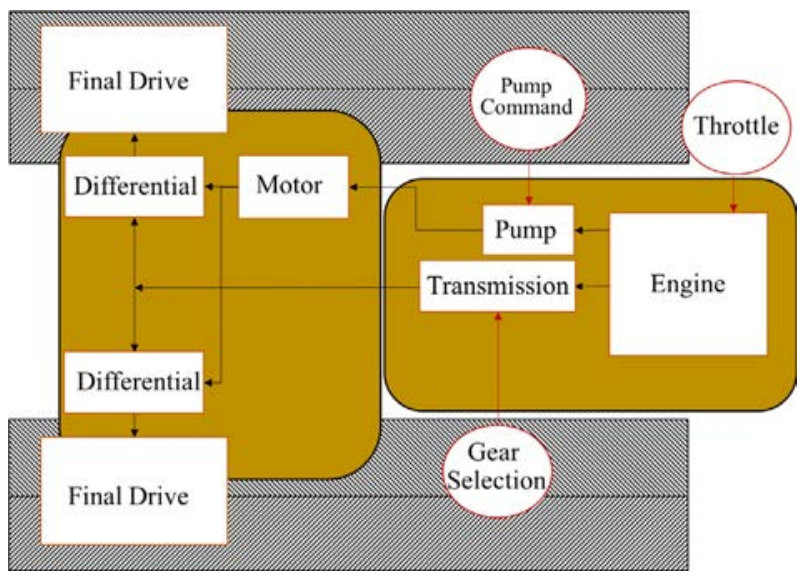

Fig. 5. Diagram of major MT865 tractor powertrain components (Caterpillar, 2002; Alexander, 1987). Inputs are denoted in red circles as the throttle $\Pi$, gear selection $g_{G R}$ and the hydraulic pump command $D_{P}$ which linearly maps to the driver's steering angle $\alpha$. (For interpretation of the references to color in this figure legend, the reader is referred to the web version of this article.)

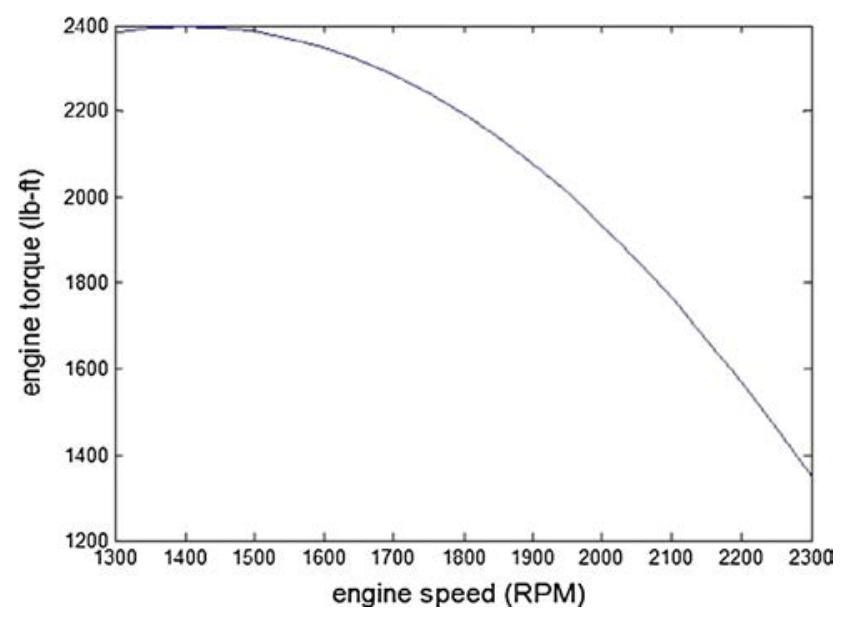

Fig. 6. Plot of the torque demand function in Eq. (36) for the engine model of an MT865 tractor. During operation, this function determines the maximum amount of torque $\tau_{E, \text { Max }}$ that can be commanded. To command $\tau_{E, \operatorname{Max}}$, a throttle $\Pi=1$ is required.

where $P_{\max }$ is the point of maximum power on the engine torque-speed curve and $\Omega_{0}$ is the engine speed at which it occurs (MathWorks, 2015). The total output power from the engine is $P(\Omega, \Pi)=\Pi g(\Omega)$ where $\Pi \in[0,1]$ is the normalized throttle command. The torque demand function is then given by

$\tau_{e}=\Pi \frac{P_{\max }}{\Omega_{0}} \frac{a n+b n^{2}-c n^{3}}{n}$

The governor is modeled as supplying zero engine torque if the engine is operating above its maximum allowable speed. It should be noted, however, that if the engine operates in this region, it can be costly with regard to simulation times. Therefore, a hyperbolic tangent function is used to taper down the throttle at higher engine speeds providing an equation for the throttle signal delivered to the engine:

$\Pi:=\Pi \tanh \left(\frac{|2300-\Omega|(2 \pi / 60)}{\chi}\right)$

The parameter $\chi$ allows for the function to be dilated and controls how close to the maximum engine speed the engine will operate.

\subsubsection{Direct drive system}

In order to simulate start-up, it is necessary to include a torque converter or direct drive mechanism in simulations since engine speeds do not match transmission shaft speeds in this operating condition. For an alternative powertrain that includes a torque converter, a control oriented model is developed by Kotwicki (1982). However, the vehicle under investigation uses a direct drive mechanism for power transfer and it is assumed to be a wet friction clutch (Băţăuş et al., 2011; Deur et al., 2005). Since the model is used here for control development, a simplified model is used (Băţăuş et al., 2011). This model is laid out in Table 1 and Fig. 7. The notations used in Table 1 are the following: $J$ is a shaft inertia, $\tau$ is a torque, $\zeta$ is a damping coefficient, $e$ refers to the engine, $c$ denotes the clutch, $P$ refers to the hydraulic variable displacement piston pump, $g_{G R}$ and $g_{F D}$ are the gear and final drive ratios, $\Gamma \in[0,1]$ is the clutch engagement command, $t, t$, in and $t$, out refer to the transmission and its input and output shafts. This model is based on the classic static model with the modification of using a continuous tanh function instead of a discontinuous sign to calculate the friction torque. This has two purposes. It incorporates viscous effects and is numerically more stable (Băţăuş et al., 2011).

Table 1

Governing equations of a wet friction clutch for slip and stick dynamics.

\begin{tabular}{|c|c|c|c|c|}
\hline \multirow{2}{*}{$\begin{array}{l}\text { State } \\
\text { Torque Capacities }\end{array}$} & \multicolumn{2}{|c|}{ Slip (Unlocked) } & \multicolumn{2}{|c|}{ Stick (Locked) } \\
\hline & $\tau_{f d}=\Gamma \tau_{f, \max , d}$ & $(38)$ & $\tau_{f s}=\Gamma \tau_{f, \max , s}$ & $(39)$ \\
\hline \multirow[t]{2}{*}{ State Equations } & $I_{e} \dot{\omega}_{e}=\tau_{e}-\zeta_{e} \omega_{e}-\tau_{c}-g_{P} \tau_{P}$ & $(40)$ & $\omega=\omega_{e}=\omega_{t, \text { in }}=g_{G R} \omega_{t, \text { out }}$ & (41) \\
\hline & $\omega_{t, \text { in }}=g_{G R} \omega_{t, \text { out }}$ & $(42)$ & $\omega_{t, \text { out }}=0.5 g_{F D}\left(\dot{\varphi}_{L}+\dot{\varphi}_{R}\right)$ & $(43)$ \\
\hline Clutch Torque & $\tau_{c}=\tau_{f d} \tanh \left(\frac{\omega_{e}-\omega_{t, i n}}{\lambda}\right)$ & $(46)$ & $\tau_{c}=\frac{J_{t} \tau_{e}+J_{e} \tau_{\text {load }}-\left(J_{t} \zeta_{e}-J_{e} \zeta_{t}\right) \omega_{e}}{J_{e}+J_{t}}$ & (47) \\
\hline Transmission Torque & $\tau_{c}=\tau_{t, i n}$ & (48) & $\tau_{e}-g_{P} \tau_{P}=\tau_{t, i n}$ & (49) \\
\hline Slip to Stick & $\omega_{e}=\omega_{t, i n} \quad$ and $\quad\left|\tau_{c}\right| \leqslant \tau_{f s}$ & $(50)$ & & \\
\hline
\end{tabular}




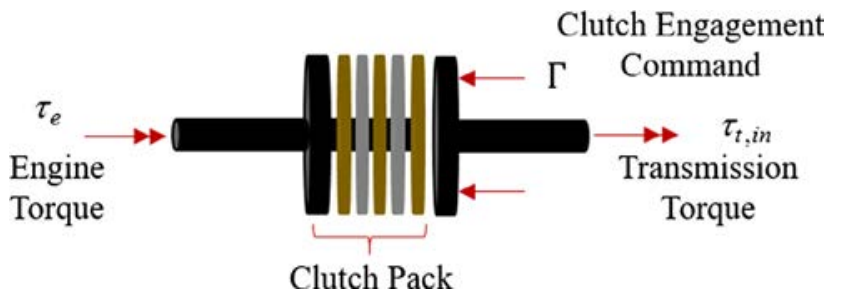

Fig. 7. Diagram of the modeled wet friction clutch. The inputs to this component are the output torque from the engine $\tau_{e}$ and the clutch engagement command $\Gamma$. The output is the input torque to the transmission $\tau_{t, i n}$.

\subsubsection{Transmission}

The transmission model is simple but captures necessary torque-speed characteristics during steady-state operation and transient gear shifts. A 16-speed transmission is modeled where the gear ratios were estimated from maximum speeds in each gear reported in Caterpillar (2002). In transient or gear-shifting conditions the dynamics are assumed to be first order:

$$
\begin{aligned}
& \delta_{t} \dot{\tau}_{t, \text { out }}+\tau_{t, \text { out }}=g_{G R, \text { new }} \tau_{t, \text { in }} \\
& \delta_{t} \dot{\omega}_{t, \text { in }}+\omega_{t, \text { in }}=g_{G R, \text { new }} \omega_{t, \text { out }}
\end{aligned}
$$

The transmission output torque $\tau_{t, \text { out }}$ is initialized at $g_{G R, o l d} \tau_{t, i n}$ and the transmission input speed $\omega_{t, i n}$ is initialized at $g_{G R, \text { new }} \omega_{t, \text { out }}$ where $g_{G R, \text { old }}$ is the gear ratio before a gear shift is commanded, $g_{G R, n e w}$ is the gear ratio of the new selected gear, $\tau_{t, i n}$ is the transmission input torque, and $\omega_{t, \text { out }}$ is the transmission output speed (Rajamani, 2006). The transmission input torque $\tau_{t, i n}$ is equal to either $\tau_{c}$ or $\tau_{e}$ depending upon whether the wet friction clutch is in the stick or slip state. There is no disruption in torque delivery since a power shift transmission is assumed. When gear shifts are complete or not occurring, the first order equations simplify to static relationships

$\tau_{t, \text { out }}=g_{G R} \tau_{t, \text { in }}$

$\omega_{t, \text { in }}=g_{G R} \omega_{t, o u t}$

\subsubsection{Differential steering}

Modern tracked vehicles use differential steering systems in order to prevent large power losses during turning maneuvers. This is done by having a hydraulic steering pump and motor that modifies the distribution of power between the two sprockets by adding more torque to one side while removing an equivalent amount from the other (Maclaurin, 2011; Maclaurin, 2007; Alexander, 1987). This allows the vehicle to yaw without having to apply brakes to one side of the vehicle. This mechanism has been investigated by Maclaurin $(2011,2007)$. In addition, the Caterpillar differential steering mechanism is reviewed by Alexander and gives a qualitative explanation on how power flows through the system (Alexander, 1987). The mechanisms described by both authors are equivalent.
Fig. 5 outlines the major components needed for differential steering.

In longitudinal motion, torque is output from the engine to the power the transmission where torque is then amplified through the selected gear ratio and distributed equally between the left and right track drivers. However, as the steering angle input is applied by a driver, the hydraulic system places an additional load on the engine that redistributes the transmission output torque between the two drivers so as to provide additional torque to one side but remove and equivalent amount from the other. This allows the vehicle to yaw.

A diagram of the modeled hydraulic system is shown in Fig. 8 where the variable displacement piston pump on the right and the fixed displacement piston motor on the left have kinematic constraints through gear ratios to the engine and differential steering module respectively. In operation, the driver commands a steering angle $\alpha$ which places an additional load on the engine and displaces hydraulic fluid into the $h$ node of the system. This causes a pressure build up which creates torque at the motor output. This torque causes the hydraulic motor to rotate and hydraulic fluid to flow out of node $h$. A similar modeling approach is used for a hydrostatic transmission in Manring and Luecke (1998). The equations governing the dynamics of the differential steering hydraulics are

$\omega_{p}=\omega_{e} g_{P}$

$\omega_{M}=g_{S T}\left(\dot{\varphi}_{R}-\dot{\varphi}_{L}\right)$

$D_{P}=\frac{\alpha}{170^{\circ}} D_{P, \operatorname{Max}} \quad \alpha \in\left[-170^{\circ}, 170^{\circ}\right]$

$Q_{h}=D_{P} \omega_{P}-D_{M} \omega_{M}$

$\dot{P}_{h}=\frac{\beta}{V_{h}} Q_{h}$

$\tau_{P}=D_{P} P_{h}$

$\tau_{M}=D_{M} P_{h}$

Here $\omega_{M}, \omega_{P}$, and $\omega_{E}$ are the motor, pump, and engine speeds. $P_{h}$ is the pressure of the hydraulic fluid in the hose, $V_{h}$ is the volume of the hose section, $\beta$ is the bulk modulus of the fluid, $D_{P}$ and $D_{M}$ are the hydraulic pump and motor

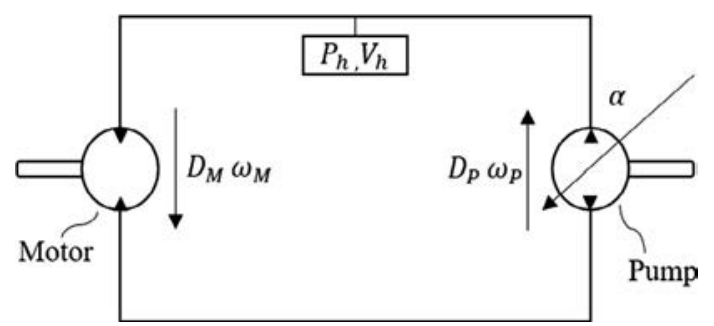

Fig. 8. Hydraulic differential steering system. The pump flow is commanded by the operators steering angle $\alpha$ and directly controls the pressure rise in the $\mathrm{h}$ section of the hose. As pressure builds up, torque is supplied to the steering motor causing it to rotate. This rotation by the motor causes hydraulic fluid to flow out of the $h$ section of the hose. 
displacements, $g_{S T}$ is the gear ratio between the hydraulic motor and drivers, and $\tau_{P}$ and $\tau_{M}$ are the load torque on the engine from the pump and the torque output from the motor. It should be noted that the flow out of the pump is explicitly commanded by the operator via steering angle $\alpha$ and the flows out of the pump and into the motor are not equivalent unless the hydraulic pressure $P_{h}$ is at a constant operating value. The torques delivered to the drivers at each track are

$\tau_{R}=\frac{1}{2} \tau_{t, o u t}+\frac{1}{2} \tau_{M} g_{S T}$

$\tau_{L}=\frac{1}{2} \tau_{t, o u t}-\frac{1}{2} \tau_{M} g_{S T}$

\section{Leader follower control}

The leader-follower control problem can roughly be defined as a regulation control problem where the follower must maintain a specified formation determined by a rectangular longitudinal and lateral offset defined in the leader's body-fixed, cartesian frame. This idea is illustrated in Fig. 9(a). This requirement is quite strict, and Barfoot and Clark (2004) have proposed regulation of a flexible curvilinear formation shown in Fig. 9(b). Here the follower follows a reference trajectory that is generated as a lateral offset from the leader's nominal trajectory where time parameterized velocities and yaw rates are computed via kinematic constraints in curvilinear coordinates (Barfoot and Clark, 2004). However, the leaders in this study are also unmanned so these nominal trajectories are absent from noise and disturbances since they are computed via a higher level planner. This approach is not readily applicable to systems with manned leader's in the loop with noisy velocity and yaw rate reference signals. Low $(2015,2014)$ adapts the method presented by Barfoot and Clark (2004) for a SUV manned leader by sampling the leader's trajectory at $20 \mathrm{~Hz}$ and generating a tracked vehicle follower reference trajectory at the sampled points. A continuous trajectory for velocity and yaw rate is then approximated using linear interpolation and followed using low level velocity and yaw rate controllers built into the tracked vehicle platform.
The method presented here uses the idea of maintaining a flexible formation but in a different way than the works discussed above These previous studies have implemented methods on two wheeled robots and a much lighter tracked vehicle under no drawbar load. There is also an implicit assumption that leader vehicle trajectories produce reference follower trajectories that are dynamically feasible. This may not always be the case for human-in-the-loop systems as proposed for SPT where manned leaders operate at $\sim 100 \%$ engine load in the highest gear ratio possible to minimize traverse times. This idea can be visualized by referring back to Fig. 9(b). Here, if the follower tractor follows a trajectory that is a perfect offset of the leader, this trajectory requires a larger arc length to be traveled in the same amount of time. If there is no extra engine torque capacity, this trajectory is not feasible. Therefore, the idea of maintaining a flexible formation is extended beyond curvilinear coordinates by using a way point following strategy. Here, way points are used as a path guide instead of providing a strict reference trajectory in combination with low level controllers for velocity and heading regulation.

\subsection{Way point following}

Instead of the leader using its trajectory to plan the follower's based on kinematic constraints in curvilinear coordinates, a way point following strategy is proposed where accurate measurements of vehicle position, speed, and heading are assumed at $10 \mathrm{~Hz}$ from GPS signal. It is also assumed that tractors can communicate CAN messages wirelessly at $10 \mathrm{~Hz}$. A diagram of this strategy is outlined in Fig. 10. The leader's trajectory is highlighted as a solid red line and way points generated from this trajectory as lateral offsets are shown as white circles which serve as a path guide for heading correction. The way point used to correct the tractor's heading is based on a tunable look-ahead distance parameter $D_{L A}$. Larger look-ahead distance values correspond to greater trajectory and path flexibility while smaller values force the tractor to strictly follow the path. To make sure the list of way points does not grow in the limit, Algorithm 1 is proposed for way point management and selection and

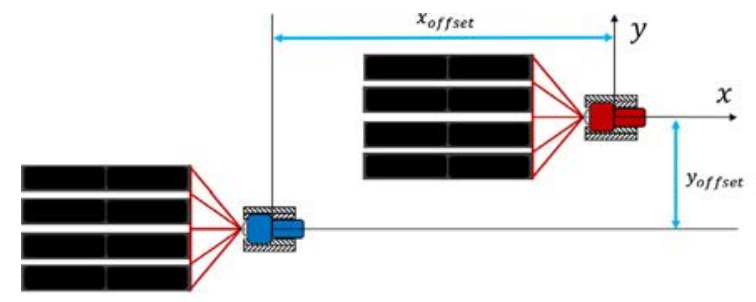

(a)

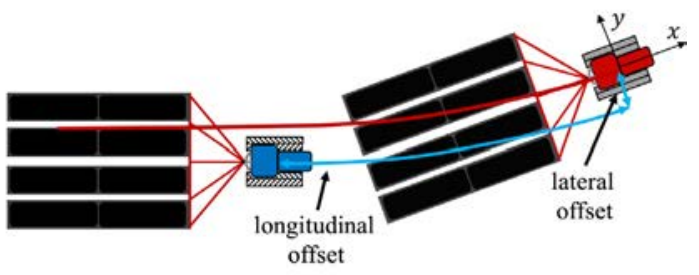

(b)

Fig. 9. (a) Rectangular coordinate leader follower formation. (b) Flexible, curvilinear coordinate leader follower formation. (a \& b) Leader tractors are colored red, follower tractors are colored blue. (For interpretation of the references to color in this figure legend, the reader is referred to the web version of this article.) 
runs at $1 \mathrm{~Hz}$ while the leader tractor's velocity is positive. Line 2 records the most recent leader position and heading measurements that are received at $10 \mathrm{~Hz}$. Line 3 computes a new way point location to add to the way point arrays $\mathbf{X}_{W P}, \mathbf{Y}_{W P}$ whose equations are given by $\theta_{\text {error }}=\arctan 2\left(\frac{Y_{W P}-Y_{\text {follower }}}{X_{W P}-X_{\text {follower }}}\right)-\theta_{\text {follower }}$

Then a way point is selected from the way point array whose distance is closest to the defined look-ahead distance $D_{L A}$ in line 6 by

Algorithm 1. Way point selection and management

Result: Updated way point array and way point for heading correction

1 while leader velocity is positive do

$2 \quad X_{\text {leader }}, Y_{\text {leader }}, \theta_{\text {leader }} \leftarrow$ Record latest leader position and heading measurements;

$3 \quad X_{W P}, Y_{W P} \leftarrow$ Compute new way point position based on the lateral offset distance $D_{\text {lat }}$ (eq.'s 65 $\& 66)$;

$\mathbf{X}_{W P}, \mathbf{Y}_{W P} \leftarrow$ Add the new way point to the way point arrays ;

$\boldsymbol{\theta}_{\text {error }} \leftarrow$ Compute heading error to each way point (eq. 67);

$X_{W P C}, Y_{W P C} \leftarrow$ Compute distance to each way point and select way point for heading correction whose distance from the vehicle is closest to the look ahead distance $D_{L A}$ (eq. 68); if $\left\|\theta_{\text {error }}\right\|>\frac{\pi}{2}$ for any way point then remove way point from way point array;

end

10 end

$X_{W P}=X_{\text {leader }}+D_{\text {lat }} \sin \left(-\theta_{\text {leader }}\right)$

$Y_{W P}=Y_{\text {leader }}+D_{\text {lat }} \cos \left(-\theta_{\text {leader }}\right)$

$$
W P C=\arg _{W P} \min \left(\left(X_{W P}-X_{\text {follower }}\right)^{2}+\left(Y_{W P}-Y_{\text {follower }}\right)^{2}-D_{L A}^{2}\right)
$$

the heading error to each way point at line 5 is computed by

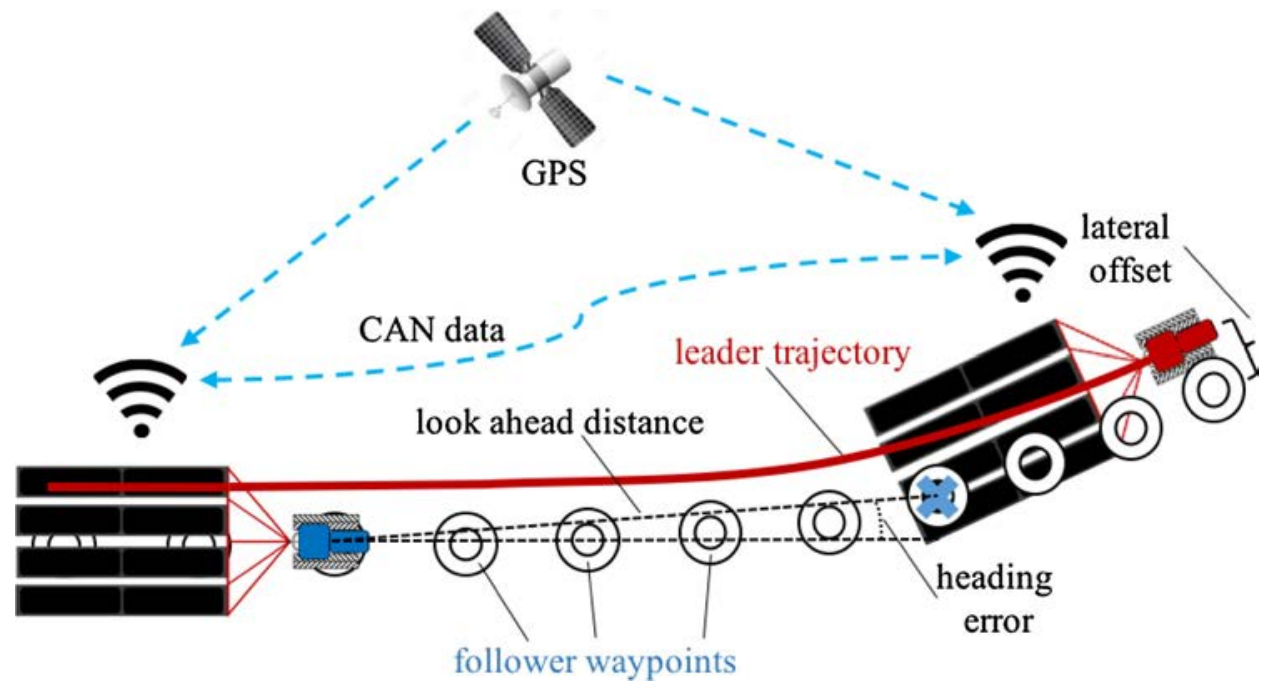

Fig. 10. Leader-follower control architecture diagram. The leader trajectory is highlighted as a solid red line and follower way points are generated as lateral offsets denoted as white circles for the follower's heading correction. The distance of this lateral offset is dictated by the parameter $D_{\text {lat }}$. The lookahead distance $D_{L A}$ is annotated in the figured where the follower makes heading corrections to the selected way point. (For interpretation of the references to color in this figure legend, the reader is referred to the web version of this article.) 
Lines 7-9 look at the entirety of both way point arrays $\mathbf{X}_{W P}, \mathbf{Y}_{W P}$ and remove any points from the lists that are behind the follower tractor, where this condition is defined as having a heading error of $\frac{\pi}{2}$ in magnitude or greater.

\subsection{Velocity and heading controllers}

In the previous section, a way point strategy is proposed for path planning of follower vehicles. These way points are used for heading correction, which indirectly maintains the lateral offset distance $D_{\text {lat }}$ defined by the manned leader. The structure for this heading controller and of a velocity controller for maintaining a longitudinal distance offset are discussed in this section.

In Section 3.1 Algorithm 1 produces a way point location for heading correction, $X_{W P C}, Y_{W P C}$, at $1 \mathrm{~Hz}$. The heading reference to the heading controller is given by

$\theta_{\text {ref }}=\arctan 2\left(\frac{Y_{W P C}-Y_{\text {follower }}}{X_{W P C}-X_{\text {follower }}}\right)$

To regulate this heading a proportional integral controller is used

$\alpha(t)=K_{p, \theta} \theta_{\text {error }}(t)+\int_{0}^{t} K_{i, \theta} \theta_{\text {error }}(t) d t$

where $\alpha$ is the driver's steering angle, $K_{p, \theta}$ is the proportional heading controller gain, $K_{i, \theta}$ is the integral heading controller gain, and $\theta_{\text {error }}(t)$ is the heading error. Since an accurate measurement of tractor heading is assumed from GPS at $10 \mathrm{~Hz}$, the controller is run at the same rate. Fig. 11 provides a diagram of the overall controller structure. To implement this controller Eq. (70) is discretized to provide difference equation. To do this, the laplace transform is taken where $s$ is the complex laplace variable to give the transfer function

$\frac{\alpha(s)}{\theta_{\text {error }}(s)}=K_{p, \theta}+K_{i, \theta} \frac{1}{s}$

To convert this continuous transfer function of the complex variable $s$ into a discrete one of the complex variable $z$, the Bilinear transform or Tustin approximation is used

$z=e^{s T_{s}} \approx \frac{1+\frac{s T_{s}}{2}}{1-\frac{s T_{s}}{2}}$

where $T_{s}=0.1$ is the sample time in seconds of the controller. The first order inverse approximation that is substituted for $s$ in Eq. (71) is

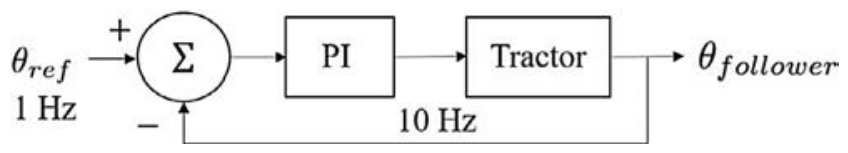

Fig. 11. Closed-loop block diagram of the unmanned tractor's heading regulation. The reference input $\theta_{\text {ref }}$ is updated at $1 \mathrm{~Hz}$. The PI controller structure is defined in Eq. (70) and updates at $10 \mathrm{~Hz}$. $s \approx \frac{2}{T_{s}} \frac{1-z^{-1}}{1+z^{-1}}$

The resulting $z$ domain transfer function is then converted back to the time domain using the $z$ transform identify $x\left[k-k_{o}\right]=z^{-k_{o}} X(z)$ (Hansen, 2014). The form of the time domain difference equation for a PI controller is given by

$\alpha[k]=-\frac{a_{1}}{a_{0}} \alpha[k-1]+\frac{b_{0}}{a_{0}} \theta_{\text {error }}[k]+\frac{b_{1}}{b_{0}} \theta_{\text {error }}[k-1]$

This process can be expedited using Matlab commands pid, tf, and c2d, where pid creates the controller structure, tf converts it to a transfer function, and c $2 \mathrm{~d}$ discretizes the continuous transfer function.

It should be noted that the transfer function between the normalized steering angle, $\alpha$, and the tractor's yaw rate, $\dot{\theta}$, can be approximated as first order. Using this knowledge, the transfer function between the normalized steering angle and the heading angle can be approximated as

$\frac{\theta(s)}{\alpha(s)}=\frac{1}{s} \frac{K_{d c}}{\delta s+1}$

where the DC gain $K_{d c}$ and time constant $\delta$ depend on vehicle velocity and the terrain assuming nominal parameters for differential steering, power-train components are known. This allows for rigorous linear control system design if $K_{d c}$ and $\delta$ are approximated across the vehicle speed range of $[0,4] \mathrm{m} / \mathrm{s}$ and the terrain parameter space.

The second low level controller used on follower tractors is for velocity regulation. The previous way point management and selection system and heading controller are responsible for maintaining the manned-leader's specified lateral offset $D_{\text {lat }}$ while the velocity controller is responsible for maintaining a specified longitudinal offset $D_{\text {long }}$. The velocity reference for the controller is given by

$v_{\text {ref }}=-k x_{e}+v_{\text {leader }}$

where $k$ is a tunable gain parameter, $x_{e}=D_{\text {long }}-d$ is the longitudinal error defined in the follower's body fixed frame in the $\mathbf{i}_{1}$ direction as in $\operatorname{Low}(2015,2014)$ where $d$ is the longitudinal distance to the leader tractor, and $v_{\text {leader }}$ is the velocity of the manned leader tractor. The parameter $d$ is illustrated graphically in Fig. 12 for clarity. Since it is assumed, that tractors receive GPS signals and can share CAN messages at $10 \mathrm{~Hz}$, the velocity reference input and control loop also runs at this rate. The controller structure and block diagram are given by Eq. (77) and Fig. 13

$\Pi_{\text {follower }}=\Pi_{\text {leader }}+K_{p, v} v_{e}(t)+\int_{0}^{t} K_{i, v} v_{e}(t) d t$

This controller uses feed-forward inputs from the lead tractor's throttle, $\Pi_{\text {leader }}$, and gear selection, $g_{G R, l e a d e r}$, in combination with a PI controller for throttle regulation. These feed forward throttle and gear inputs from the leader simplify the controller design and increase robustness since lower gain values can be used for adequate performance. 


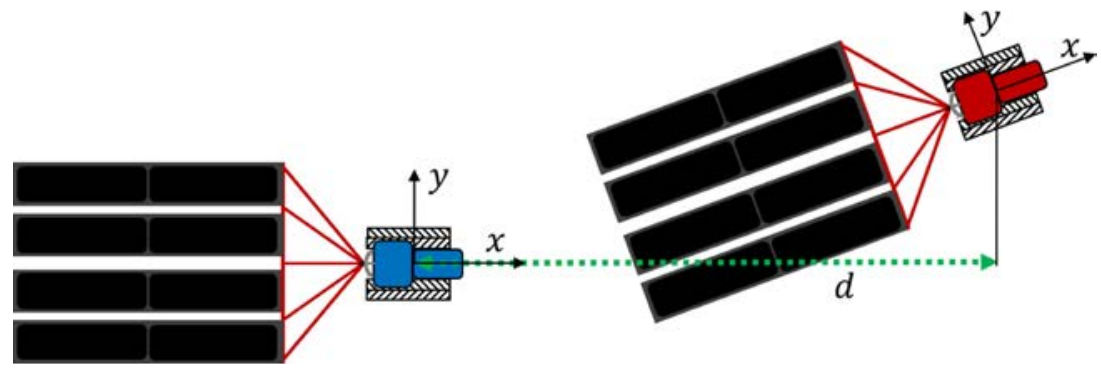

Fig. 12. Diagram of one leader follower pair where the leader and follower are colored red and blue respectively. The distance from the follower to the leader $d$ is denoted with a dotted green line. (For interpretation of the references to color in this figure legend, the reader is referred to the web version of this article.)

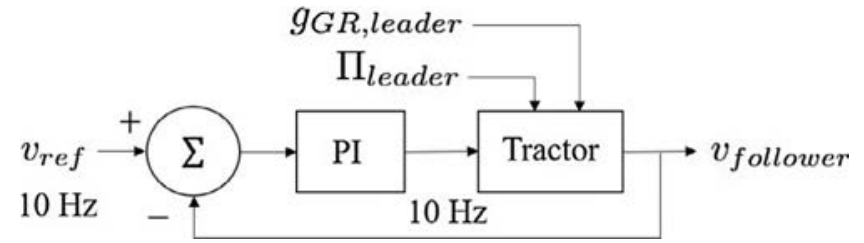

Fig. 13. Closed-loop block diagram of the unmanned tractor's speed. The reference input $v_{\text {ref }}$ is updated at $10 \mathrm{~Hz}$. The controller structure is defined in Eq. (77) which uses a combination of a PI controller with feed-forward terms $\Pi_{\text {leader }}$ and $g_{G R, \text { leader }}$ that are the manned leader's throttle and gear selection at $10 \mathrm{~Hz}$.

The velocity controller is discretized using the same methods as the heading controller where the time domain equation is converted to its laplace transform equivalent, discretized into the $z$ transform, and converted back into the time domain in the form of a difference equation

$$
\begin{aligned}
& \Pi_{\text {follower }}[k]=\Pi_{\text {leader }}[k]+\Pi_{P I}[k] \\
& \Pi_{P I}[k]=-\frac{a_{1}}{a_{0}} \Pi_{P I}[k-1]+\frac{b_{0}}{a_{0}} v_{e}[k]+\frac{b_{1}}{a_{0}} v_{e}[k-1]
\end{aligned}
$$

\section{Simulation results}

The numerical experiment in this section simulates one leader-follower tractor pair. Fig. 14 shows the path traversed of both tractors along with snapshots of position for initial and terminal simulation positions. Way points that are lateral offsets of the leader's trajectory used for fol-

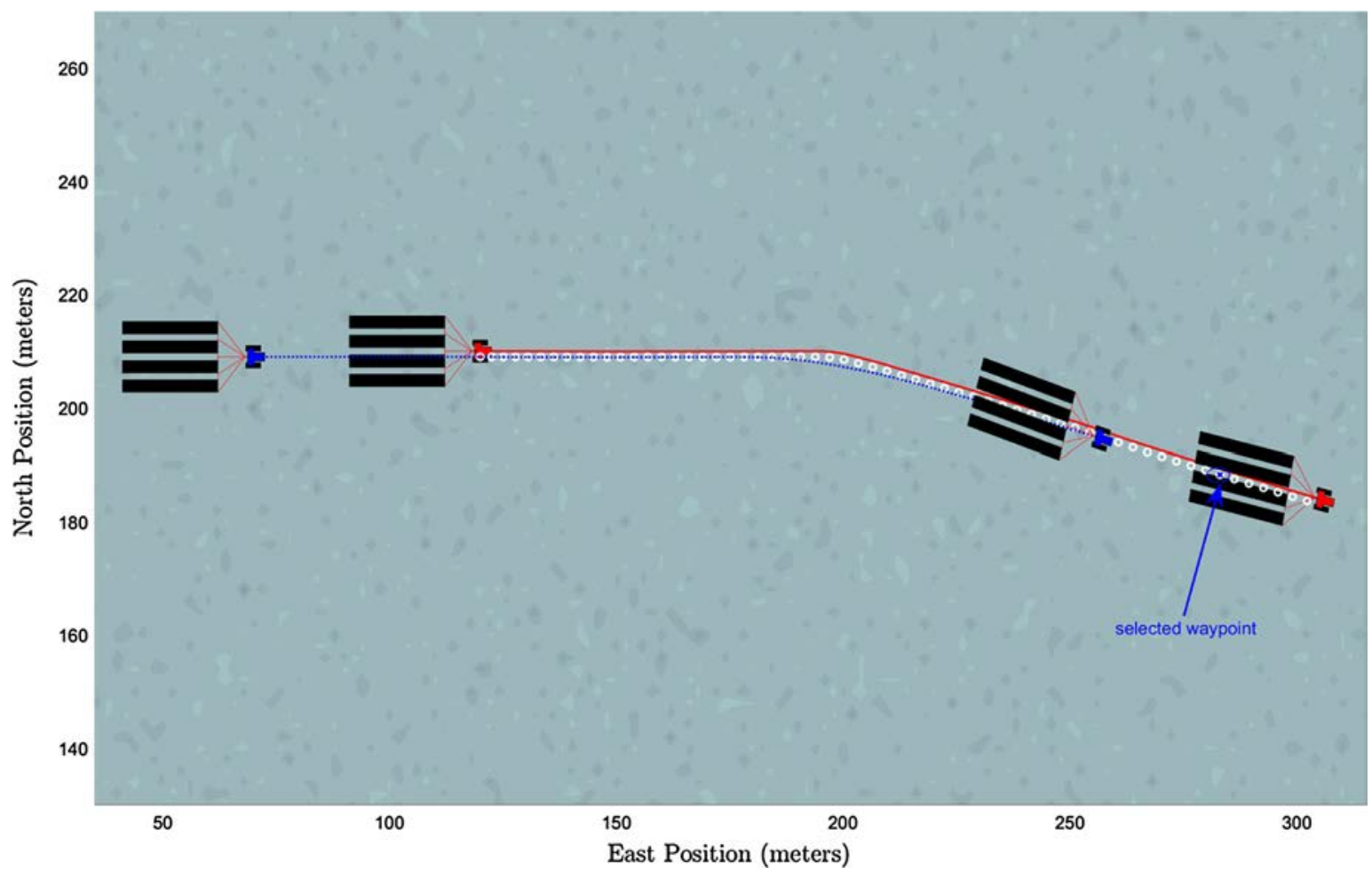

Fig. 14. One leader-follower tractor pair. Starting locations are [120,210] and [70,209] for the leader and follower respectively. Snapshots of both vehicles are taken at the starting and terminal locations of the simulation. The paths traversed of each tractor for the leader and follower are highlighted as solid and dotted lines. Way points used for follower heading correction are denoted as circles. The way point that is selected at the end of the simulation for heading correction has a $\mathrm{x}$ over top of the waypoint circle. 
lower heading correction are denoted as circles and the $\mathrm{x}$ denotes the current way point being used. Fig. 15 shows plots of vehicle speed $\left\|v_{T}\right\|$, yaw rate $\dot{\theta}$, left and right slip ratios $i_{L}$ and $i_{R}$, engine speed $\Omega$ and drawbar arm angle $\phi$. Initial $[X, Y]$ starting locations for the leader and follower are $[120,210]$ and $[70,209]$ respectively. This corresponds to a column formation where the follower vehicle is offset $1 \mathrm{~m}$ to the right and $40 \mathrm{~m}$ behind relative to the leader. The manned leader's trajectory is dictated using a combination of open loop and closed-loop commands. Open loop commands include throttle, $\Pi_{\text {leader }}=[0.9,0.9$, $0.9,0.98]^{T}$, and gear selections, $g_{G R, \text { leader }}=[9,10,11,12]^{T}$, for the time vector $t=[0,3,8,20]^{T}$ seconds. Closed-loop commands for heading are regulated using a PI controller and generated using a sequence of two way points with $\left[X_{W P, L}, Y_{W P, L}\right]=[210,1000]$ for $t \in[0,20)$ seconds and $\left[X_{W P, L}, Y_{W P, L}\right]=[20,1000]$ for $t \in[20,60]$ where $X_{W P, L}$ and $Y_{W P, L}$ are the $\mathrm{X}$ and $\mathrm{Y}$ coordinates the leader drives towards. Controller gains for leader heading correction are $K_{p, \theta}=2 \frac{\mathrm{deg}}{\mathrm{deg}}$ and $K_{i, \theta}=0.05 \frac{\mathrm{deg}}{\mathrm{deg}}$. Initially the leader vehicle drives straight but the second way point in the sequence forces it to take an abrupt right turn. This is intentionally induced into the simulation so that payload stability issues are elicited. This is illustrated in the bottom right plot as the drawbar arm angle $\phi$ in Fig. 15 where large oscillations are seen. The advantage of maintaining a flexible formation using the look ahead approach described in Section 3.1 is that the follower vehicle does not need to mimic the leader's nominal trajectory as with other techniques. Instead, this strategy forces the follower vehicle to make several minor corrections ahead of time to loosely follow the way point path. The benefit from using this approach can be seen when comparing the trajectory of the drawbar arm angle of the leader and follower in Fig. 15. The oscillations that are present in the leader's trajectory are rejected by the follower to maintain the payload stable at the rear of the tractor. The controller gains for the follower in this numerical experiment are $k=0.1 \frac{\mathrm{m} / \mathrm{s}}{\mathrm{m}}, K_{p, v}=5 \frac{\mathrm{m} / \mathrm{s}}{\mathrm{m} / \mathrm{s}}$, $K_{p, i}=1 \frac{\mathrm{m} / \mathrm{s}}{\mathrm{m} / \mathrm{s}}, K_{p, \theta}=2 \frac{\mathrm{deg}}{\operatorname{deg}}$ and $K_{i, \theta}=0.05 \frac{\mathrm{deg}}{\mathrm{deg} .}$. The look ahead distance $D_{L A}$ is set to $40 \mathrm{~m}$.

Optimal leader tractor operation occurs when throttle and gear selection inputs are chosen to maximize engine output power and vehicle speed to minimize round-trip traverse times. In theory, the lead vehicle should operate with a throttle command of $\Pi_{\text {leader }}=1$ in the highest gear selection possible. However, in simulations using this open-loop throttle command, the follower tractor has difficulty maintaining the specified formation offset. This is due to the fact that no additional torque is available if the unmanned tractor falls behind due to any disturbance. Furthermore, if the follower tractor has to make heading corrections to follow the way point path, no additional torque is available to power the differential steering hydraulics. Consequently, some limitations on the manned leader's throttle input are required. Simulation results show $T_{\text {leader }} \leqslant 0.98$ to be
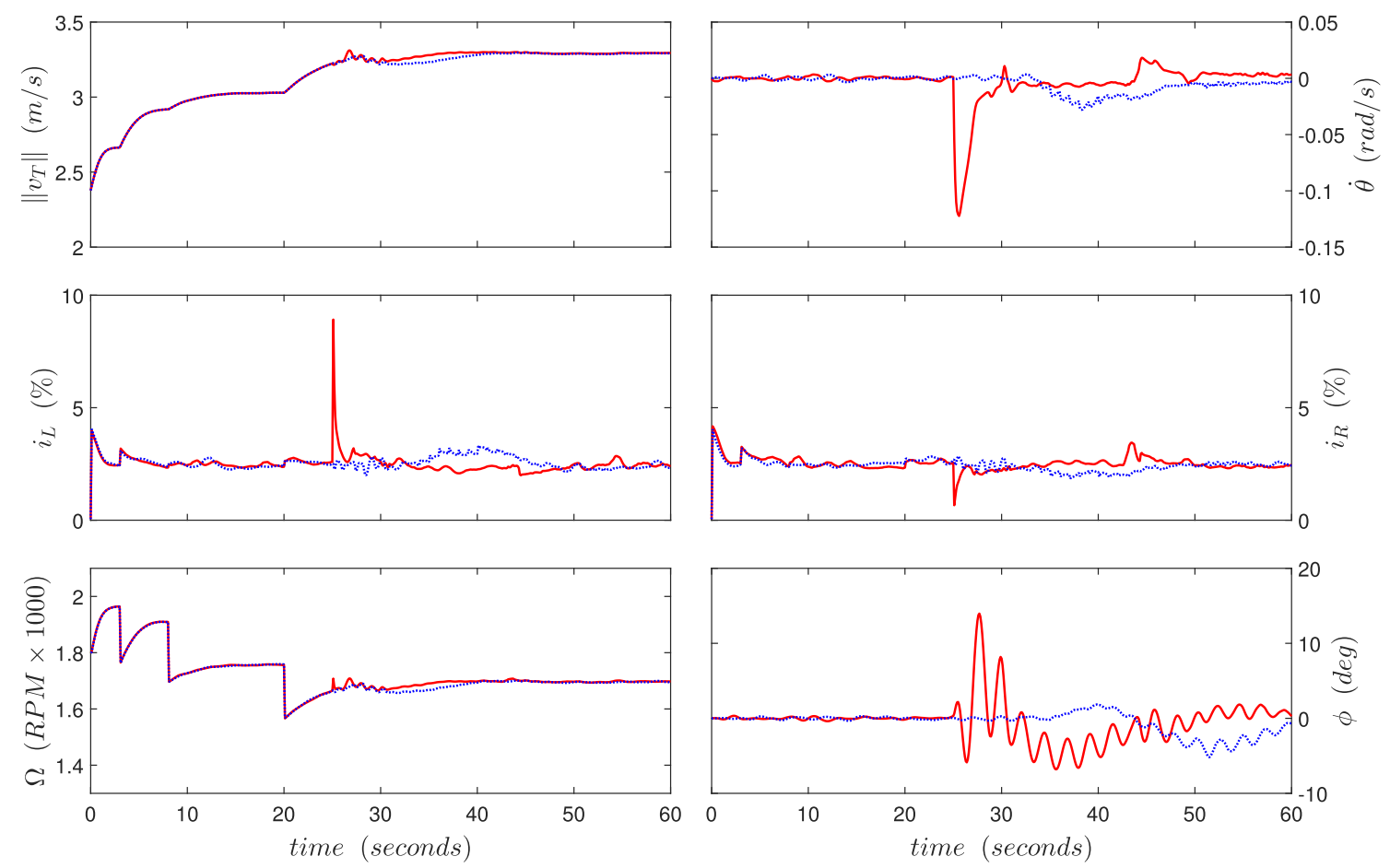

Fig. 15. Plots of vehicle speed $\left\|v_{T}\right\|$, yaw rate $\dot{\theta}$, left and right slip ratios $i_{L}$ and $i_{R}$, engine speed $\Omega$ and drawbar arm angle $\phi$ for the manned leader and unmanned follower tractors. The manned leader's and unmanned follower's trajectories are solid and dotted lines respectively. 
sufficient. The effect of an additional load from the differential steering hydraulics can be seen when looking at plots of engine speed in Fig. 15 between 30 and $40 \mathrm{~s}$ where both vehicles see a reduction in engine RPM.

\section{Conclusion}

A comprehensive tracked vehicle dynamics model has been developed including the effects of the powertrain, terrain-vehicle interaction, and payload on deformable terrain with relatively low computational cost. This can be used as a powerful tool for fast, iterative model-based design to test autonomous tractor algorithms and tune controllers across different operating conditions and expected terrains.

In this paper, a partially autonomous tractor system is proposed with a human in the loop specifically taking the form a manned leader, autonomous follower vehicle pair. Emphasis is placed on maintaining a flexible formation so that the unmanned vehicle has the capability to reject human error in driving. This is done using a combination of way points as a path guide along with a look-ahead technique. Simulation results show the effectiveness of this approach: when a manned leader takes an abrupt turn and experiences large drawbar oscillations, the unmanned follower keeps its payload stable.

Future work for implementation will investigate the expected, discrete terrain parameter space to approximate linear plant dynamics for heading correction across different vehicle speeds as discussed in Section 3.2. Then controllers can be designed using linear system techniques. Other work could include developing an adaptive lookahead distance for unmanned vehicles based on the trailer stability of the manned leader. This way, follower vehicles do not need to deviate from the way point path by an unnecessary amount.

\section{Acknowledgement}

This work was supported by NASA grant NNX-10AL97H.

\section{Appendix A.}

$$
\begin{aligned}
\mathbf{M}(1,1)= & m_{S D}+m_{T} \\
\mathbf{M}(1,2)= & \mathbf{M}(2,1)=0 \\
\mathbf{M}(1,3)= & \mathbf{M}(3,1)=\frac{1}{2} m_{S D}\left(2 L_{A} \sin (\phi)+L_{S D} \sin (\psi)\right. \\
& \left.+2 L_{T S} \sin (\psi)\right) \\
\mathbf{M}(1,4)= & \mathbf{M}(4,1)=L_{A} m_{S D} \sin (\phi) \\
\mathbf{M}(1,5)= & \mathbf{M}(5,1)=\frac{1}{2} m_{S D} \sin (\psi)\left(L_{S D}+2 L_{T S}\right) \\
\mathbf{M}(2,2)= & m_{S D}+m_{T}
\end{aligned}
$$

$$
\begin{aligned}
\mathbf{M}(2,3)= & \mathbf{3}, \mathbf{2}=-\frac{1}{2} m_{S D}\left(2 L_{T A}+2 L_{A} \cos (\phi)+L_{S D} \cos (\psi)\right. \\
& \left.+2 L_{T S} \cos (\psi)\right) \\
\mathbf{M}(2,4)= & \mathbf{M}(4,2)=-L_{A} m_{S D} \cos (\phi) \\
\mathbf{M}(2,5)= & -\frac{1}{2} m_{S D} \cos (\psi)\left(L_{S D}+2 L_{T S}\right) \\
\mathbf{M}(3,3)= & m_{S D} L_{T A}^{2}+2 m_{S D} \cos (\phi) L_{T A} L_{A}+m_{S D} \cos (\psi) L_{T A} L_{S D} \\
+ & 2 m_{S D} \cos (\psi) L_{T A} L_{T S}+m_{S D} L_{A}^{2}+m_{S D} \cos (\phi-\psi) L_{A} L_{S D} \\
+ & 2 m_{S D} \cos (\phi-\psi) L_{A} L_{T S}+\frac{1}{4} m_{S D} L_{S D}^{2}+m_{S D} L_{S D} L_{T S} \\
+ & m_{S D} L_{T S}^{2}+J_{S D}+J_{T} \\
\mathbf{M}(3,4)= & \mathbf{M}(4,3)=\frac{1}{2}\left(L _ { A } m _ { S D } \left(2 L_{A}+2 L_{T A} \cos (\phi)\right.\right. \\
& \left.\left.+L_{S D} \cos (\phi-\psi)+2 L_{T S} \cos (\phi-\psi)\right)\right) \\
\mathbf{M}(3,5)= & \mathbf{M}(5,3)=J_{S D}+\frac{1}{4} L_{S D}^{2} m_{S D}+L_{T S}^{2} m_{S D}+L_{S D} L_{T S} m_{S D} \\
& +\frac{1}{2}\left(L_{T A} L_{S D} m_{S D} \cos (\psi)\right)+L_{T A} L_{T S} m_{S D} \cos (\psi) \\
& +\frac{1}{2} L_{A} L_{S D} m_{S D} \cos (\phi-\psi)+L_{A} L_{T S} m_{S D} \cos (\phi-\psi)
\end{aligned}
$$

$\mathbf{M}(4,4)=L_{A}^{2} m_{S D}$

$\mathbf{M}(4,5)=\mathbf{M}(5,4)=\frac{1}{2} L_{A} m_{S D} \cos (\phi-\psi)\left(L_{S D}+2 L_{T S}\right)$

$\mathbf{M}(5,5)=\frac{1}{4} m_{S D} L_{S D}^{2}+m_{S D} L_{S D} L_{T S}+m_{S D} L_{T S}^{2}+J_{S D}$

$\mathbf{M}(6,6)=\mathbf{M}(6,7)=J_{S}$

$\mathbf{B}(1,1)=F_{L}+F_{R}-R_{L}-R_{R}+R_{S D, X} \cos (\psi)$

$-R_{S D, Y} \sin (\psi)+\dot{\theta} m_{S D} v_{y}+\dot{\theta} m_{T} v_{y}$

- $L_{T A} \dot{\theta}^{2} m_{S D}-\dot{\phi}^{2} L_{A} m_{S D} \cos (\phi)$

- $\dot{\theta}^{2} L_{A} m_{S D} \cos (\phi)-\frac{1}{2} \dot{\psi}^{2} L_{S D} m_{S D} \cos (\psi)$

$-\frac{1}{2} \dot{\theta}^{2} L_{S D} m_{S D} \cos (\psi)-\dot{\psi}^{2} L_{T S} m_{S D} \cos (\psi)$

- $\dot{\theta}^{2} L_{T S} m_{S D} \cos (\psi)-2 \dot{\phi} \dot{\theta} L_{A} m_{S D} \cos (\phi)$

$-\dot{\psi} \dot{\theta} L_{S D} m_{S D} \cos (\psi)-2 \dot{\psi} \dot{\theta} L_{T S} m_{S D} \cos (\psi)$

$\mathbf{B}(2,1)=R_{l L F}+R_{l L R}+R_{I R F}+R_{I R R}+R_{S D, Y} \cos (\psi)$

$+R_{S D, X} \sin (\psi)-\dot{\theta} m_{S D} v_{x}-\dot{\theta} m_{T} v_{x}$

- $\dot{\phi}^{2} L_{A} m_{S D} \sin (\phi)-\dot{\theta}^{2} L_{A} m_{S D} \sin (\phi)$

$-\frac{1}{2} \dot{\psi}^{2} L_{S D} m_{S D} \sin (\psi)-\frac{1}{2} \dot{\theta}^{2} L_{S D} m_{S D} \sin (\psi)$

$-\dot{\psi}^{2} L_{T S} m_{S D} \sin (\psi)-\dot{\theta}^{2} L_{T S} m_{S D} \sin (\psi)$

- $2 \dot{\phi} \dot{\theta} L_{A} m_{S D} \sin (\phi)-\dot{\psi} \dot{\theta} L_{S D} m_{S D} \sin (\psi)$

$-2 \dot{\psi} \dot{\theta} L_{T S} m_{S D} \sin (\psi)$ 


$$
\begin{aligned}
\mathbf{B}(3,1)= & \frac{1}{2} F_{R} b-\frac{1}{2} F_{L} b+\frac{1}{2} R_{L} b-\frac{1}{2} R_{R} b-\frac{1}{2} R_{S D, Y} L_{S D} \\
& -R_{S D, Y} L_{T S}+\frac{1}{4} l R_{l L F}-\frac{1}{4} l R_{l L R}+\frac{1}{4} l R_{l R F}-\frac{1}{4} l R_{l R R} \\
& -R_{S D, Y} L_{A} \cos (\phi-\psi)+R_{S D, X} L_{A} \sin (\phi-\psi) \\
& -R_{S D, Y} L_{T A} \cos (\psi)-R_{S D, X} L_{T A} \sin (\psi)+L_{T A} \dot{\theta} m_{S D} v_{x} \\
& +L_{T A} \dot{\phi}^{2} L_{A} m_{S D} \sin (\phi)+\frac{1}{2} L_{T A} \dot{\psi}^{2} L_{S D} m_{S D} \sin (s i) \\
& +L_{T A} \dot{\psi}^{2} L_{T S} m_{S D} \sin (\psi)+\frac{1}{2} \dot{\phi}^{2} L_{A} L_{S D} m_{S D} \sin (\phi-\psi) \\
& +\dot{\phi}^{2} L_{A} L_{T S} m_{S D} \sin (\phi-\psi)-\frac{1}{2} \dot{\psi}{ }^{2} L_{A} L_{S D} m_{S D} \sin (\phi-\psi) \\
& -\dot{\psi}{ }^{2} L_{A} L_{T S} m_{S D} \sin (\phi-\psi)+\dot{\theta} L_{A} m_{S D} v_{x} \cos (\phi) \\
& +\frac{1}{2} \dot{\theta} L_{S D} m_{S D} v_{x} \cos (\psi)+\dot{\theta} L_{T S} m_{S D} v_{x} \cos (\psi) \\
& +\dot{\theta} L_{A} m_{S D} v_{y} \sin (\phi)+\frac{1}{2} \dot{\theta} L_{S D} m_{S D} v_{y} \sin (\psi) \\
& +\dot{\theta} L_{T S} m_{S D} v_{y} \sin (\psi)+2 L_{T A} \dot{\phi} \dot{\theta} L_{A} m_{S D} \sin (\phi) \\
& +L_{T A} \dot{\psi} \dot{\theta} L_{S D} m_{S D} \sin (\psi)+2 L_{T A} \dot{\psi} \dot{\theta} L_{T S} m_{S D} \sin (\psi) \\
& +\dot{\phi} \dot{\theta} L_{A} L_{S D} m_{S D} \sin (\phi-\psi)+2 \dot{\phi} \dot{\theta} L_{A} L_{T S} m_{S D} \sin (\phi-\psi) \\
& -\dot{\psi} \dot{\theta} L_{A} L_{S D} m_{S D} \sin (\phi-\psi)-2 \dot{\psi} \dot{\theta} L_{A} L_{T S} m_{S D} \sin (\phi-\psi) \\
& \\
&
\end{aligned}
$$

$$
\begin{aligned}
\mathbf{B}(4,1)= & -\frac{1}{2} L_{A}\left(2 R_{S D, Y} \cos (\phi-\psi)-2 R_{S D, X} \sin (\phi-\psi)\right. \\
& +\dot{\psi}^{2} L_{S D} m_{S D} \sin (\phi-\psi)+\dot{\theta}^{2} L_{S D} m_{S D} \sin (\phi-\psi) \\
& +2 \dot{\psi}^{2} L_{T S} m_{S D} \sin (\phi-\psi)+2 \dot{\theta}^{2} L_{T S} m_{S D} \sin (\phi-\psi) \\
& -2 \dot{\theta} m_{S D} v_{x} \cos (\phi)-2 \dot{\theta} m_{S D} v_{y} \sin (\phi) \\
& +2 L_{T A} \dot{\theta}^{2} m_{S D} \sin (\phi)+2 \dot{\psi} \dot{\theta} L_{S D} m_{S D} \sin (\phi-\psi) \\
& \left.+4 \dot{\psi} \dot{\theta} L_{T S} m_{S D} \sin (\phi-\psi)\right)
\end{aligned}
$$

$\mathbf{B}(5,1)=\frac{1}{2}\left(L_{S D}+2 L_{T S}\right)\left(\dot{\phi}^{2} L_{A} m_{S D} \sin (\phi-\psi)-R_{S D, Y}\right.$

$+\dot{\theta}^{2} L_{A} m_{S D} \sin (\phi-\psi)+\dot{\theta} m_{S D} v_{x} \cos (\psi)$

$+\dot{\theta} m_{S D} v_{y} \sin (\psi)-L_{T A} \dot{\theta}^{2} m_{S D} \sin (\psi)$

$\left.+2 \dot{\phi} \dot{\theta} L_{A} m_{S D} \sin (\phi-\psi)\right)$

$\mathbf{B}(6,1)=\tau_{L}-F_{L} r-\zeta \dot{\varphi}_{L}$

$\mathbf{B}(7,1)=\tau_{R}-F_{R} r-\zeta \dot{\varphi}_{R}$

\section{Appendix B. Supplementary material}

Supplementary data associated with this article can be found, in the online version, at http://dx.doi.org/10.1016/ j.jterra.2017.05.002.

\section{References}

Alexander, G.F., 1987. Caterpillar's New D8N Tractor with Differential Steering. Tech. Rep. SAE Technical Paper.

Barfoot, T.D., Clark, C.M., 2004. Motion planning for formations of mobile robots. Robot. Autonom. Syst. 46 (2), 65-78.

Băţăuş, M., Maciac, A., Oprean, M., Vasiliu, N., 2011. Automotive clutch models for real time simulation. Proc. Roman. Acad. Ser. A: Math. Phys. Tech. Sci. Informat. Sci.

Caterpillar, 2002. Challenger MT800 Series. <http://www.miltoncat.com/ products/PerformanceHandbook/Handbook/Documents/MT800Prod-Bulletin.pdf>.

Deur, J., Petric, J., Asgari, J., Hrovat, D., 2005. Modeling of Wet Clutch Engagement Including a Thorough Experimental Validation. Tech. Rep. SAE Technical Paper.

Eiyo, F., Kitano, M., 1984. Study on Controllability and Stability of High Speed Tracked Vehicles. Tech. Rep. DTIC Document.

Ferretti, G., Girelli, R., 1999. Modelling and simulation of an agricultural tracked vehicle. J. Terrramech. 36 (3), 139-158.

Hansen, E.W., 2014. Fourier Transforms: Principles and Applications. John Wiley \& Sons.

Kitano, M., Jyozaki, H., 1976. A theoretical analysis of steerability of tracked vehicles. J. Terrramech. 13 (4), 241-258.

Kitano, M., Kuma, M., 1977. An analysis of horizontal plane motion of tracked vehicles. J. Terrramech. 14 (4), 211-225.

Kotwicki, A.J., 1982. Dynamic Models for Torque Converter Equipped Vehicles. Tech. Rep. SAE Technical Paper.

Le, A.T., Rye, D.C., Durrant-Whyte, H.F., 1997. Estimation of track-soil interactions for autonomous tracked vehicles. Proceedings, 1997 IEEE International Conference on Robotics and Automation, vol. 2. IEEE, pp. 1388-1393.

Lever, J.H., Weale, J.C., 2012. High efficiency fuel sleds for polar traverses. J. Terrramech. 49 (3), 207-213.

Low, C.B., 2014. A flexible virtual structure formation keeping control design for nonholonomic mobile robots with low-level control systems, with experiments. In: 2014 IEEE International Symposium on Intelligent Control (ISIC). IEEE, pp. 1576-1582.

Low, C.B., 2015. A flexible leader-follower formation tracking control design for nonholonomic tracked mobile robots with low-level velocities control systems. In: 2015 IEEE 18th International Conference on Intelligent Transportation Systems. IEEE, pp. 2424-2431.

Maclaurin, B., 2007. A skid steering model with track pad flexibility. J. Terrramech. 44 (1), 95-110.

Maclaurin, B., 2011. A skid steering model using the Magic Formula. J. Terrramech. 48 (4), 247-263.

Manring, N., Luecke, G.R., 1998. Modeling and designing a hydrostatic transmission with a fixed-displacement motor. J. Dynam. Syst. Meas. Control 120 (1), 45-49.

MathWorks, 2015. Generic Engine. <http://www.mathworks.com/ help/physmod/sdl/ref/genericengine.html $>$.

Murakami, H., Watanabe, K., Kitano, M., 1992. A mathematical model for spatial motion of tracked vehicles on soft ground. J. Terramech. 29 (1), 71-81.

Rajamani, R., 2006. Vehicle Dynamics and Control, second ed. Springer, New York.

Rubinstein, D., Hitron, R., 2004. A detailed multi-body model for dynamic simulation of off-road tracked vehicles. J. Terrramech. 41 (2), $163-173$.

Wong, J., 2008. Theory of Ground Vehicles, first \& fourth ed. John Wiley \& Sons.

Zhang, X., Geimer, M., Grandl, L., Kammerbauer, B., 2009. Method for an electronic controlled platooning system of agricultural vehicles. In: 2009 IEEE International Conference on Vehicular Electronics and Safety (ICVES). IEEE, pp. 156-161. 


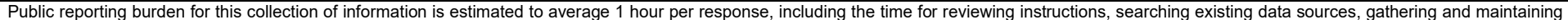

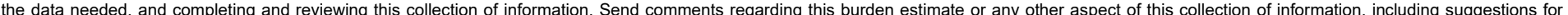

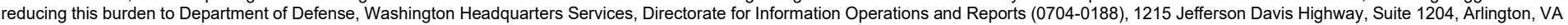

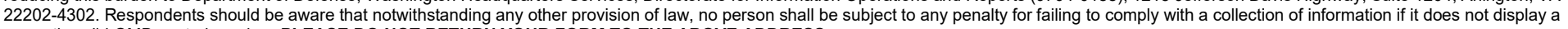
currently valid OMB control number. PLEASE DO NOT RETURN YOUR FORM TO THE ABOVE ADDRESS.
1. REPORT DATE (DD-MM-YYYY)
February 2022

\section{TITLE AND SUBTITLE}

Dynamics Modeling and Robotic-Assist, Leader-Follower Control of Tractor Convoys
3. DATES COVERED (From - To)

5a. CONTRACT NUMBER

5b. GRANT NUMBER

NNX-10AL97H

5c. PROGRAM ELEMENT NUMBER

\section{5d. PROJECT NUMBER}

5e. TASK NUMBER

5f. WORK UNIT NUMBER

8. PERFORMING ORGANIZATION REPORT NUMBER

ERDC/CRREL MP-22-3
Dartmouth College

14 Engineering Drive

Hanover, NH 03755

Thayer School of Engineering

Hanover, NH 03755
72 Lyme Road

Hanover, NH 03755

9. SPONSORING / MONITORING AGENCY NAME(S) AND ADDRESS(ES)

National Aeronautics and Space Administration

Washington, DC 20546

10. SPONSOR/MONITOR'S ACRONYM(S)

NASA

11. SPONSOR/MONITOR'S REPORT NUMBER(S)

\section{DISTRIBUTION / AVAILABILITY STATEMENT}

Approved for public release; distribution is unlimited.

\section{SUPPLEMENTARY NOTES}

This article was originally published online in the Journal of Terramechanics on 27 June 2017.

This work was supported by NASA grant NNX-10AL97H.

\section{ABSTRACT}

This paper proposes a generalized dynamics model and a leader-follower control architecture for skid-steered tracked vehicles towing polar sleds. The model couples existing formulations in the literature for the powertrain components with the vehicle-terrain interaction to capture the salient features of terrain trafficability and predict the vehicles response. This coupling is essential for making realistic predictions of the vehicles traversing capabilities due to the power-load relationship at the engine output. The objective of the model is to capture adequate fidelity of the powertrain and off-road vehicle dynamics while minimizing the computational cost for model based design of leader-follower control algorithms. The leader-follower control architecture presented proposes maintaining a flexible formation by using a look-ahead technique along with a way point following strategy. Results simulate one leader-follower tractor pair where the leader is forced to take an abrupt turn and experiences large oscillations of its drawbar arm indicating potential payload instability. However, the follower tractor maintains the flexible formation but keeps its payload stable. This highlights the robustness of the proposed approach where the follower vehicle can reject errors in human leader driving.

\section{SUBJECT TERMS}

Multi-body dynamics; Tracked vehicle; Leader-follower control

16. SECURITY CLASSIFICATION OF:
\begin{tabular}{|c|c|c|}
\hline a. REPORT & b. ABSTRACT & c. THIS PAGE \\
Unclassified & Unclassified & Unclassified \\
\hline
\end{tabular}

\begin{tabular}{c|c|}
$\begin{array}{c}\text { 17. LIMITATION } \\
\text { OF ABSTRACT }\end{array}$ & $\begin{array}{c}\text { 18. NUMBER } \\
\text { OF PAGES }\end{array}$ \\
UU & 21 \\
\hline
\end{tabular}

\section{9a. NAME OF RESPONSIBLE PERSON}

19b. TELEPHONE NUMBER (include area code) 